This document was prepared in conjunction with work accomplished under Contract No. DE-AC09-96SR18500 with the U. S. Department of Energy.

\title{
DISCLAIMER
}

This report was prepared as an account of work sponsored by an agency of the United States Government. Neither the United States Government nor any agency thereof, nor any of their employees, nor any of their contractors, subcontractors or their employees, makes any warranty, express or implied, or assumes any legal liability or responsibility for the accuracy, completeness, or any third party's use or the results of such use of any information, apparatus, product, or process disclosed, or represents that its use would not infringe privately owned rights. Reference herein to any specific commercial product, process, or service by trade name, trademark, manufacturer, or otherwise, does not necessarily constitute or imply its endorsement, recommendation, or favoring by the United States Government or any agency thereof or its contractors or subcontractors. The views and opinions of authors expressed herein do not necessarily state or reflect those of the United States Government or any agency thereof. 


\section{TRITIUM RESERVOIR STRUCTURAL PERFORMANCE PREDICTION (U)}

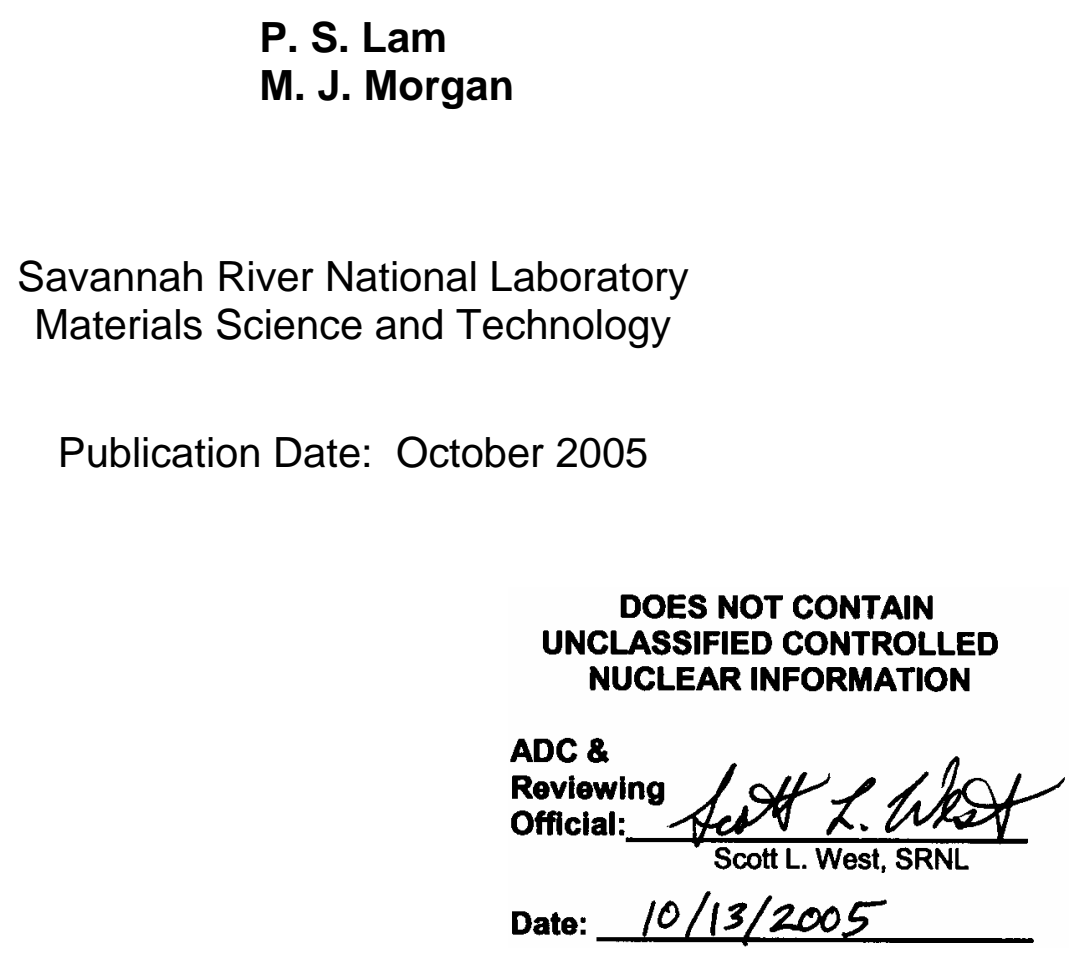

Patent Status

This internal management report is being transmitted without DOE patent clearance, and no further dissemination or publication shall be made of the report without prior approval of the DOE-SR patent counsel.

\section{Westinghouse Savannah River Company Savannah River Site Aiken, SC 29808}

This document was prepared in connection with work done under Contract No. DE-AC09-96SR18500 with the U. S. Department of Energy 


\section{DISCLAIMER}

This report was prepared as an account of work sponsored by an agency of the United States Government. Neither the United States Government nor any agency thereof, nor any of their employees, makes any warranty, express or implied, or assumes any legal liability or responsibility for the accuracy, completeness, or usefulness of any information, apparatus, product, or process disclosed, or represents that its use would not infringe privately owned rights. Reference herein to any specific commercial product, process, or service by trade name, trademark, manufacturer, or otherwise does not necessarily constitute or imply its endorsement, recommendation, or favoring by the United States Government or any agency thereof. The views and opinions of authors expressed herein do not necessarily state or reflect those of the United States Government or any agency thereof. 
DOCUMENT: $\quad$ WSRC-TR-2005-00251

TITLE: $\quad$ Tritium Reservoir Structural Performance Prediction (U)

APPROVALS

P. S. Lam, Author

Materials Applications \& Process Technology Group

SRNL-Materials Science and Technology

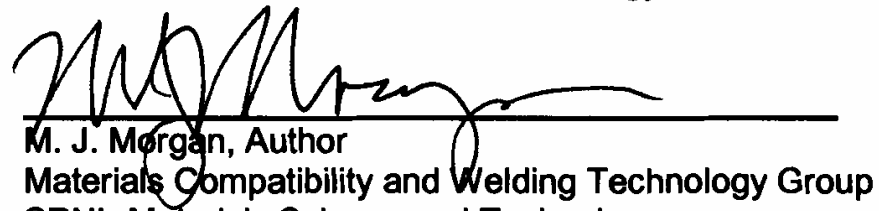

SRNL-Materials Science and Technology

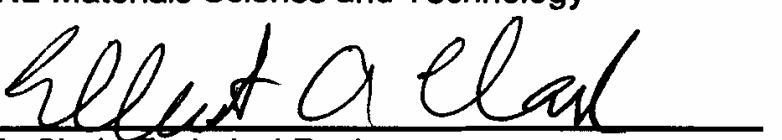

E. A. Clark, Technical Reviewer

Materials Compatibility and Welding Technology Group SRNL-Materials Science and Technology

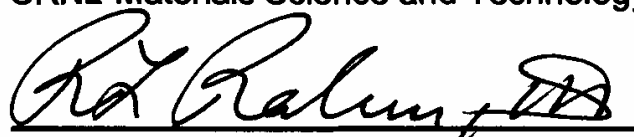

R. L. Rabin, III, Program Manager

Defense Programs Engineering

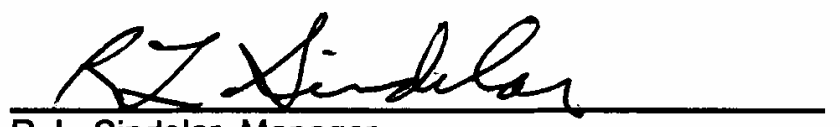

R. L. Sindelar, Manager

Materials Applications \& Process Technology Group

SRNL-Materials Science and Technology

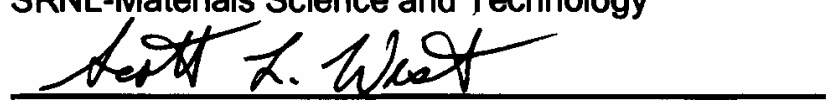

S. L. West, Manager

Materials Compatibility and Welding Technology Group SRNL-Materials Science and Technology

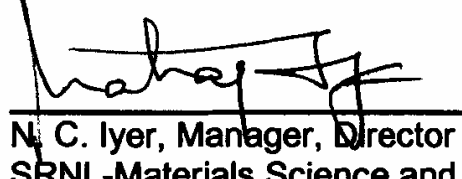

SRNL-Materials Science and Technology
Date: October 13. 2005

Date: October 13,2005

Date: 13 October 2005

Date: Oct 20,2005

Date: $10 / 13 / 2005$

Date: $10 / 13 / 2005$

Date: $10 / 20 / 2005$ 
WSRC-TR-2005-00251

Table of Contents

$\underline{\text { Section }}$

Page

SUMMARY

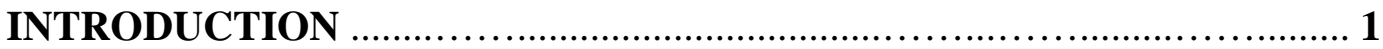

BENCH-MARKING UNEXPOSED RESERVOIR BURST TEST .............. 2

Material Testing and Tensile Properties ..................................... 2

Adjustment for Tensile Test Data .......................................... 5

Finite Element Analysis ....................................................... 7

Finite Element Model ......................................................... 7

Comparison of Deformation …................................................. 7

Prediction of Failure Location ....................................................... 8

Comparison of Finite Element Prediction and Test Data .................... 10

Failure Criterion for Burst Prediction ........................................ 11

PREDICTION OF TRITIUM-EXPOSED RESERVOIRS ........................ 13

Exposed Material: Elastic-Perfectly-Plastic Behavior ................ 13

Exposed Material - Helium-3 Concentration-Dependent

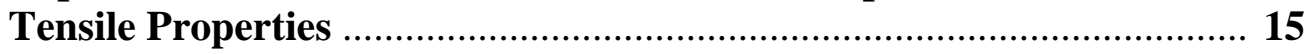

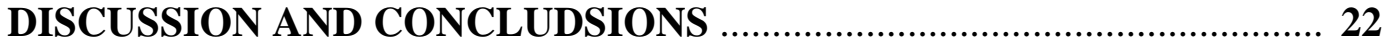

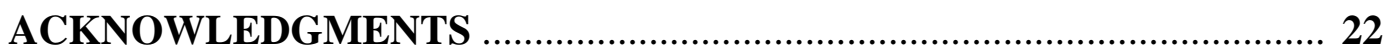

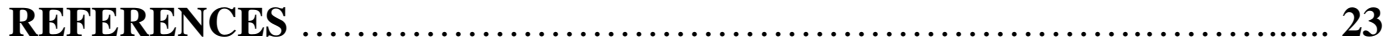


WSRC-TR-2005-00251

Table of Contents (continued)

\section{LIST OF TABLES}

Table Number

Page

1 Tensile property of HERF 316 due to helium concentration

\section{LIST OF FIGURES}

Figure Number

Page

1 Typical longitudinal and transverse tensile specimens harvested from a mock, non-exposed tritium reservoir using EDM

2 Engineering stress-engineering strain curve as-tested from a slightly curved tensile specimen ............................................................................. 4

3 Corrected engineering stress-engineering strain curve ................................ 4

4 True stress-true strain curve and Bridgman correction for the failure point ... 5

5 Post-burst configuration of a mockup pipe ......................................... 8

6 Mises stress contours (a, b, and c) and the finite element meshes (d, e, and f), respectively, for several prototypic burst test specimens with various designs. 9

7 (a) Mises stress contour in MPa and (b) the corresponding equivalent plastic strain (PEEQ) contour for a typical test specimen

8 Comparison of the actual test data and the finite element prediction using a stress-strain curve with yield stress scaled to $63 \mathrm{ksi}$

9 Burst pressure and volume ductility as functions of maximum plastic strain in the test specimen sidewall

10 Determination of burst instability as a function of thickness percentage that is affected by tritium in the sidewall of the specimen

11 Reduction of ductility as a function of tritium-affected material in the sidewall

12 Typical tensile property change due to tritium exposure (Reproduced from [12])

13 Tensile property change with respect to helium-3 concentration for various stainless steels (Reproduced from [10])

14 Simplified stress-strain curves for exposed HERF 316 at various helium concentrations

15 Determination of volume reduction and burst pressure for helium concentration 125 APPM at various depths of penetration 
16 Determination of volume reduction and burst pressure for helium concentration 250 APPM at various depths of penetration

17 Determination of volume reduction and burst pressure for helium concentration 500 APPM at various depths of penetration

18 Volume reduction as a function of helium concentration for various depths of penetration

19 Contours of (a) Mises stress in MPa and (b) equivalent plastic strain (PEEQ) in a test specimen with $60 \%$ of sidewall thickness containing helium with concentration of 500 APPM 


\section{SUMMARY}

The burst test is used to assess the material performance of tritium reservoirs in the surveillance program in which reservoirs have been in service for extended periods of time. A materials system model and finite element procedure were developed under a Savannah River Site Plant-Directed Research and Development (PDRD) program to predict the structural response under a full range of loading and aged material conditions of the reservoir. The results show that the predicted burst pressure and volume ductility are in good agreement with the actual burst test results for the unexposed units. The material tensile properties used in the calculations were obtained from a curved tensile specimen harvested from a companion reservoir by Electric Discharge Machining (EDM).

In the absence of exposed and aged material tensile data, literature data were used for demonstrating the methodology in terms of the helium- 3 concentration in the metal and the depth of penetration in the reservoir sidewall. It can be shown that the volume ductility decreases significantly with the presence of tritium and its decay product, helium-3, in the metal, as was observed in the laboratory-controlled burst tests.

The model and analytical procedure provides a predictive tool for reservoir structural integrity under aging conditions. It is recommended that benchmark tests and analysis for aged materials be performed. The methodology can be augmented to predict performance for reservoir with flaws.

\section{INTRODUCTION}

The burst test is an industry standard approach to evaluate pressure vessel/pipeline design and weld joint performance. In the case of tritium reservoirs, the burst test is an established protocol in evaluating the material performance after extended tritium service.

The ductility of the tritium-aged material is significantly reduced as a result of helium-3 precipitated in the microstructure of the metal due to tritium decay, in addition to the effect of hydrogen (tritium) embrittlement. However, the burst testing for previously loaded reservoirs is very difficult and costly because of challenges associated with tritium off-gas and contamination control. As a result, it is desirable that an analytical/numerical technique be developed to complement, or even provide an alternative to, the burst testing. The method should be capable of predicting the burst pressure, and more importantly, the volume ductility which is a measurement of the change in volume of the reservoir at burst failure. A Defense Programs Plant-Directed Research \& Development (PDRD) task was initiated to develop such an analytical approach.

The first part of the report describes the development of the model, analytic procedure, and material data for predicting reservoir burst performance. The tensile specimens were harvested from unexposed reservoirs by using Electric Discharge Machining (EDM). 
Because the tensile specimens are curved, the test data must be adjusted. The procedure is described in the report. This set of material properties was used to benchmark the burst test of an unexposed reservoir. It can be shown that the finite element result is in good agreement with the burst test data when the stress-strain curve was scaled so the yield stress is $63 \mathrm{ksi}$, within the acceptable range of forged stainless steel (Type 316L). The actual failure location coincides with the calculated location of maximum Mises stress or maximum plastic strain. A strain-based failure criterion is proposed, that is, the volume ductility is proportional to the maximum equivalent plastic strain that occurs in the sidewall. However, a complete material database including the aged material properties and accurate construction details of the specific reservoirs are needed to validate this failure criterion.

The second part of this report describes the approach of evaluating tritium-aged materials to facilitate input into the model. Burst tests for several tritium-exposed reservoirs have been carried out. Mudflat cracks are typically found in the post-test examination of the fracture surface. It was postulated that these cracks may be formed at the yield stress of the exposed material and are responsible for the reduction of ductility of the reservoirs. In the absence of actual tensile properties for the exposed material, two material idealizations were assumed: 1 ) elastic-perfectly plastic behavior (i.e., nonhardening); and 2) simplified stress-strain relationships based on literature data in terms of the helium-3 concentration in the metal. Both approximations show that the burst pressures are similar but the reduction of volume ductility is significant when higher helium concentration is accumulated in the metal.

Since the tritium and helium profiles in the reservoir wall are sensitive to the loading and service histories of the reservoir, the burst properties (pressure and volume ductility) may be reservoir dependent. Finite element analysis using reservoir-specific models is proposed when the exposed tensile properties are available [1,2] and included in the material database.

\section{BENCH-MARKING UNEXPOSED RESERVOIR BURST TEST}

\section{Material Testing and Tensile Properties}

The material of construction of the reservoirs under consideration in this report is a forged austenitic stainless steel of type 316L, which has a yield strength in the range of 55 to $75 \mathrm{ksi}$ (the yield strength of a typical annealed stainless steel is about $30 \mathrm{ksi}$ ). The minimum ultimate tensile strength (UTS) is $85 \mathrm{ksi}$. Using the standard round tension test specimen as specified in American Society for Testing and Materials (ASTM) E 8 Standard Test Methods for Tension Testing of Metallic Materials ( 0.5 in. diameter with 2 in. gage length), the elongation and the reduction of area should meet, respectively, 35\% and $40 \%$.

Tensile specimens from a mock, non-exposed tritium reservoir were harvested in the longitudinal and transverse directions with respect to the orientation of the reservoir using 
an EDM [1,2]. As seen from Figure 1, the specimens are curved with a typical thickness of 0.023 in., which was chosen to obtain averaged tensile properties of tritium and helium-bearing material. The specimen width and the reduced section length are 0.062 in. and 0.3 in., respectively. The dimensions of the specimens were chosen to minimize the curvature effects for the load frame. Both longitudinal and transverse tensile specimens were tested. A typical stress-strain curve for the longitudinal specimen (from Specimen R2SL-2 No. 33) is shown in Figure 2. The initial portion of the stress-strain data (see Fig. 2) were affected by the specimen curvature. This effect is accounted for and the actual tensile flow curve is recovered by the procedure described in the next section. The corrected engineering stress-engineering strain curve (Fig. 3) can be converted to the true measures (Fig. 4) for analyses involving large deformation such as in the event of burst test.
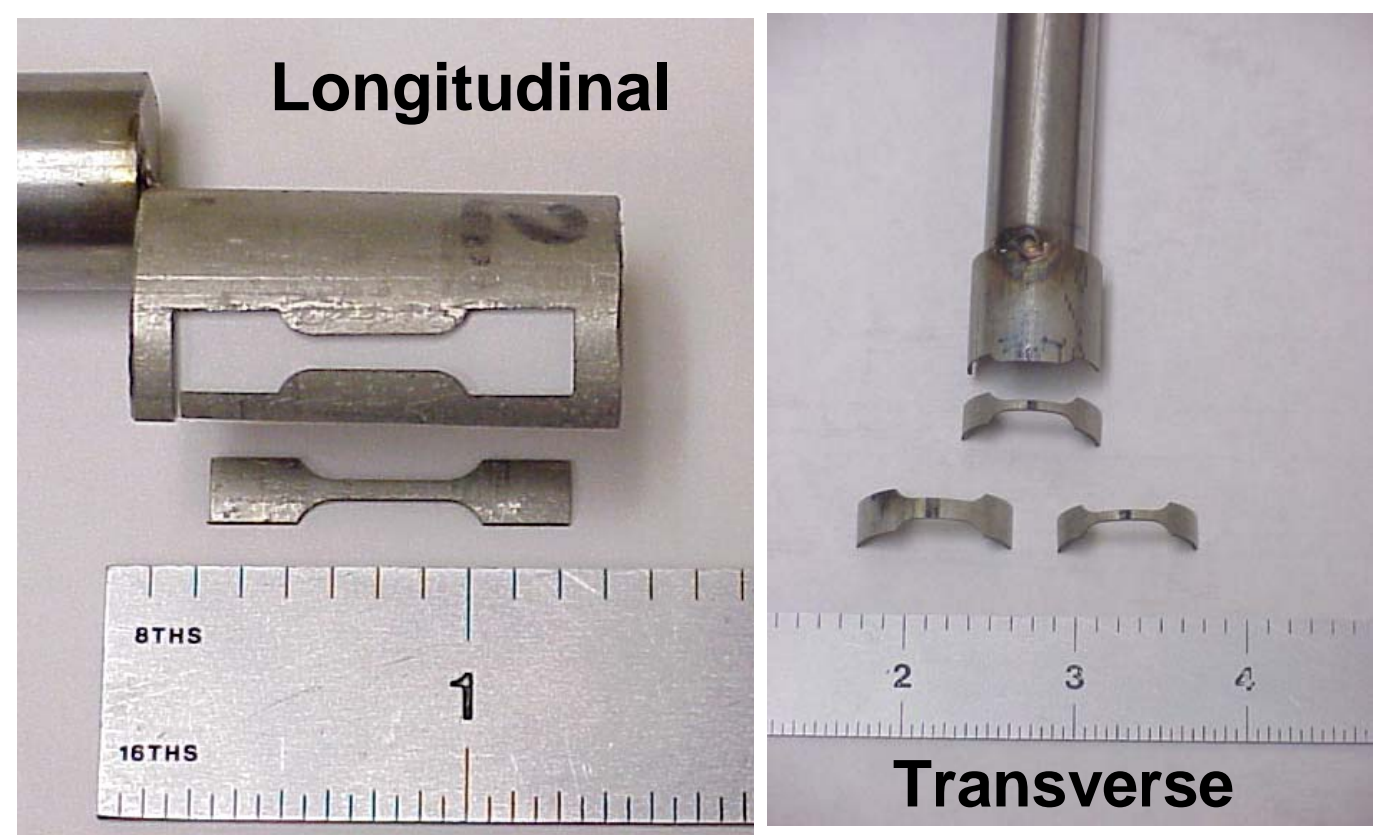

Figure 1 Typical longitudinal and transverse tensile specimens harvested from a mock, non-exposed tritium reservoir using EDM 


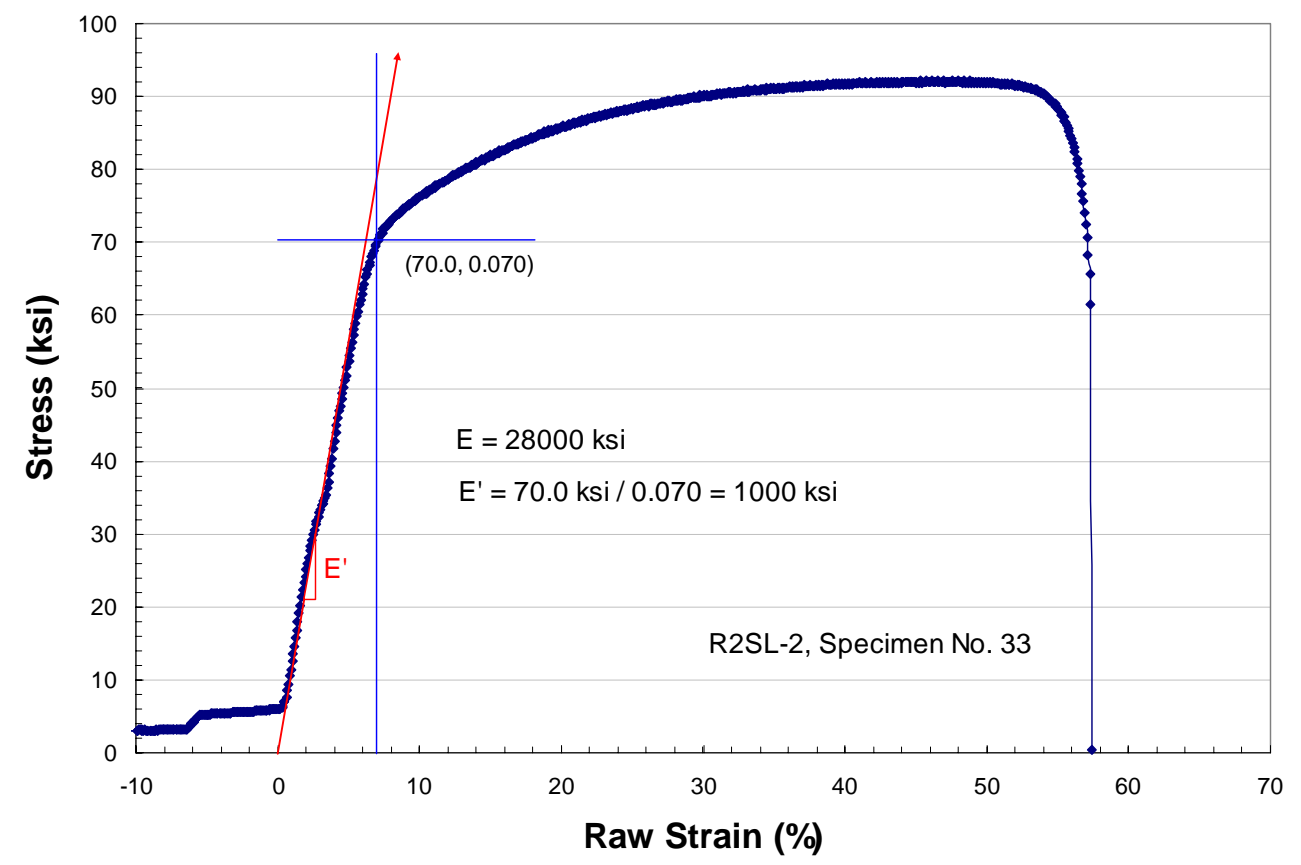

Figure 2 Engineering stress-engineering strain curve as-tested from a slightly curved tensile specimen

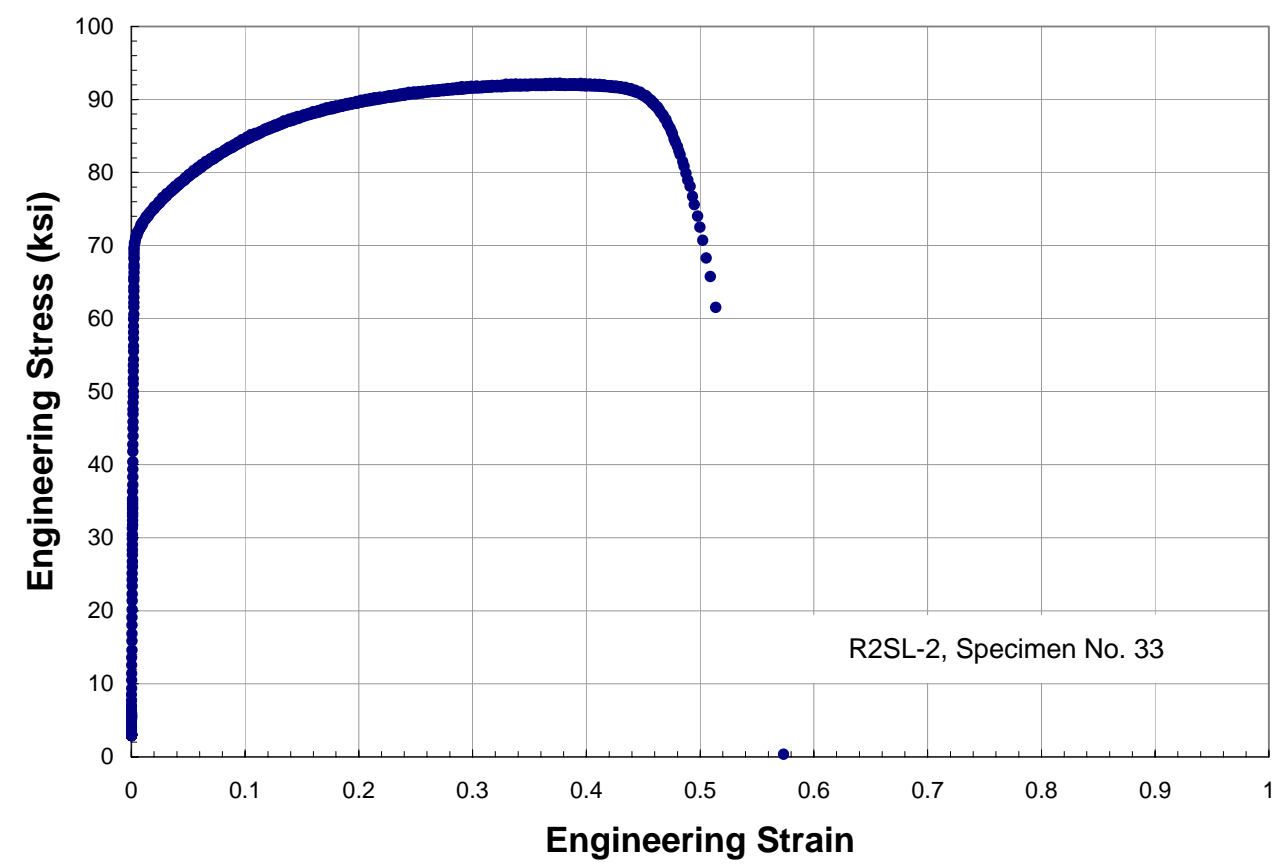

Figure 3 Corrected engineering stress-engineering strain curve 


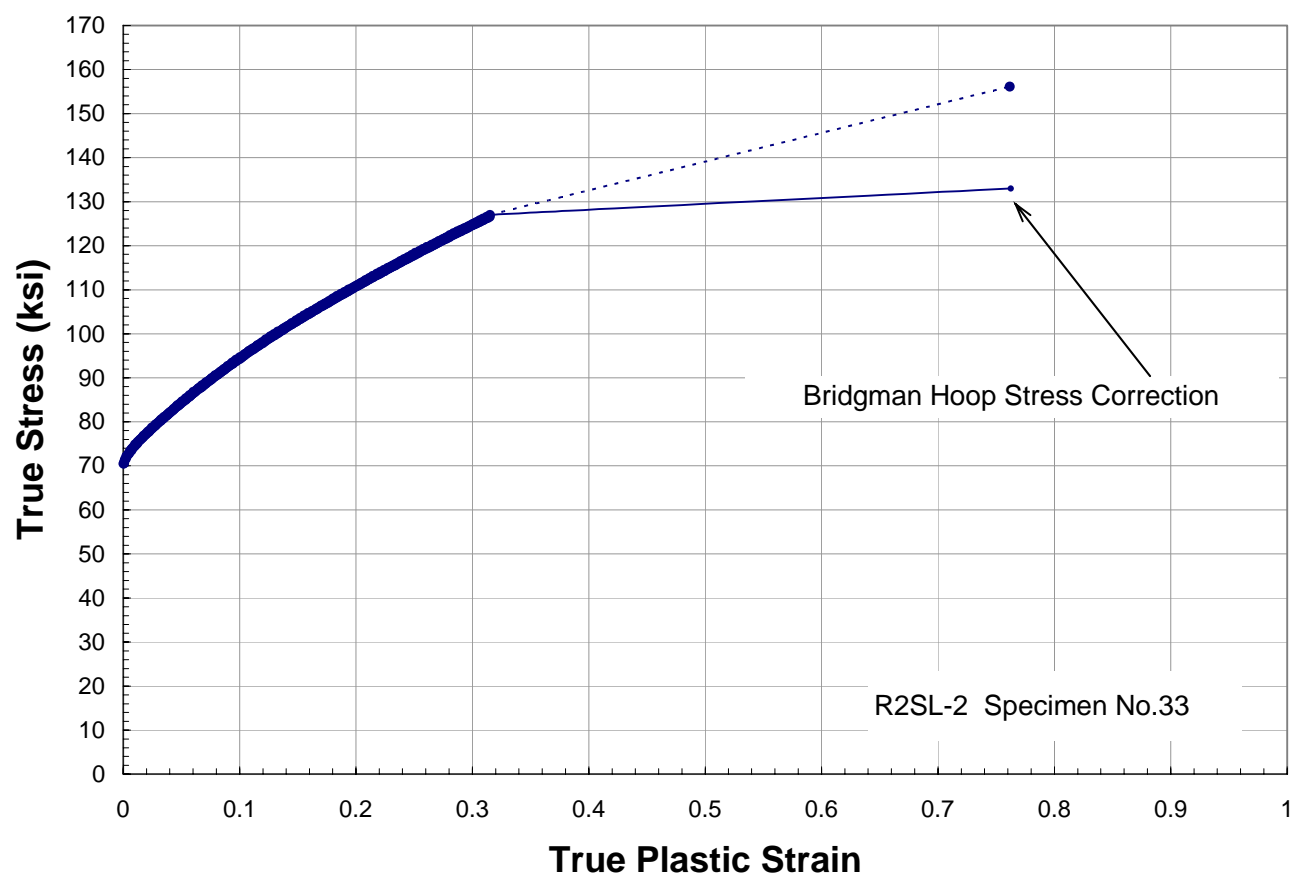

Figure 4 True stress-true strain curve and Bridgman correction for the failure point

\section{Adjustment for Tensile Test Data}

The procedure for correcting the initial portion of the stress-strain curve, and the subsequent conversion to the true stress-true strain curve with Bridgman hoop stress correction for the failure stress and strain is described in the following:

1. The standard Young's modulus (or the modulus of elasticity) for stainless steels (28,000 ksi ) is used for all specimens because this value is in general insensitive to this class of metallic materials at room temperature. The tensile tests performed in this study were not optimized or designed for the determination of the Young's modulus at very small strain range.

2. A straight line is identified in the initial portion of the engineering stressengineering strain curve (see Fig. 2). Note that the slope of the line (E')is different from the Young's modulus (E), which is set to 28,000 ksi. The stress value at which the stress-strain curve begins to deviate from the initial straight line is considered as the yield stress of the material at zero plastic strain (the definition is different from the standard $0.2 \%$ offset yield stress).

3. The plastic deformation is defined as the total deformation minus the "as-tested" elastic deformation. In terms of engineering stress and engineering strain, it is defined as $\varepsilon_{\mathrm{pl}}^{\mathrm{E}}=\varepsilon_{\text {tot }}^{\mathrm{E}}-\sigma^{\mathrm{E}} / \mathrm{E}^{\prime}$, where $\varepsilon_{\mathrm{pl}}^{\mathrm{E}}$ is the engineering plastic strain, $\varepsilon_{\text {tot }}^{\mathrm{E}}$ is the total engineering strain from the test data, $\sigma^{\mathrm{E}}$ is the engineering stress, and $\mathrm{E}^{\text {' is }}$ measured from the slope of the initial straight line in Figure 2. 
4. The actual elastic strain $\left(\varepsilon_{\mathrm{el}}^{\mathrm{E}}\right)$ is defined in the traditional manner. That is $\varepsilon_{\mathrm{el}}^{\mathrm{E}}=\sigma^{\mathrm{E}} / \mathrm{E}$, where $\mathrm{E}$ is the standard Young's modulus of the material.

5. The corrected total engineering strain $\left(\varepsilon_{\text {tot }}^{\text {corr }}\right)$ is therefore defined as $\varepsilon_{\text {tot }}^{\text {corr }}=\varepsilon_{\text {el }}^{\mathrm{E}}+\varepsilon_{\mathrm{pl}}^{\mathrm{E}}$

6. After the strains are corrected, Figure 2 can be re-plotted as in Figure 3.

7. By standard conversion, Figure 3 is then re-plotted as the true stress ( $\sigma$ )-true total strain $\left(\varepsilon_{\text {tot }}^{\mathrm{T}}\right)$ curve. This is necessary for the large deformation finite element analysis, for example, using the ABAQUS code [3], in which the true stress-trueplastic strain curve is used (Fig. 4). The true plastic strain $\left(\varepsilon_{\mathrm{pl}}\right)$ is defined as $\varepsilon_{\mathrm{pl}}=\varepsilon_{\text {tot }}^{\mathrm{T}}-\sigma / \mathrm{E}$

8. In Figure 4, the true stress-true plastic strain curve, any data point after necking takes place, or beyond the ultimate tensile strength (UTS) where the maximum uniform elongation occurs, should be corrected because the stress state is no longer uniaxial. For practical purpose, all the data points after UTS are discarded except the failure point, for which the final cross-sectional area of the test specimen can be measured. The original Bridgman correction [4-6] for the round bar tensile specimens are formulated as $\sigma_{\mathrm{f}}=\mathrm{P}_{\mathrm{f}}\left(\pi \mathrm{R}_{\mathrm{f}}^{2}\left(1+2 \mathrm{R}_{\mathrm{N}} / \mathrm{R}_{\mathrm{f}}\right) \ln \left(1+\mathrm{R}_{\mathrm{f}} / 2 \mathrm{R}\right)\right)^{-1}$ where $\sigma_{f}$ is the (true) failure stress, $P_{f}$ is the load at failure, $R_{f}$ is the final measured gage section radius, and $R_{N}$ is the measured radius of curvature of the necking region. The true strain at failure based on the reduction of area is calculated by $\varepsilon_{\mathrm{f}}^{\mathrm{T}}=2 \ln \left(\mathrm{R}_{\mathrm{o}} / \mathrm{R}_{\mathrm{f}}\right)$ where $R_{o}$ is the undeformed radius of the gage section.

Instead of using the original Bridgman formulation, a simplified correction $[7,8]$ that employed an empirical curve developed by Bridgman for steels was used: $\sigma_{\mathrm{B}}^{\mathrm{T}}=\mathrm{B} \sigma$ where $\sigma_{\mathrm{B}}^{\mathrm{T}}$ is the corrected true stress, $\sigma$ is the true stress calculated as the load per unit current cross-sectional area, and $\mathrm{B}=0.83-0.186 \log \varepsilon_{\text {tot }}^{\mathrm{T}}$ for $0.15 \leq \varepsilon_{\text {tot }}^{\mathrm{T}} \leq 3$ No correction is needed for $\varepsilon_{\text {tot }}^{\mathrm{T}}<0.15$. Note that in the above expression, log is the 10-based logarithm. This simplified method is suitable for the flat specimens with rectangular cross-sections.

As an example, the failure point in the stress-strain curve is corrected as shown in Figure 4 (see the solid curve), which can be readily used in the large deformation finite element analysis, such as the burst test prediction in this report. For this study, only the unexposed mechanical properties for this type of reservoir steel were available. Additional testing for tritium aged specimens has recently been conducted [2] and will be included in future analysis. 


\section{Finite Element Analysis}

The burst test analysis involves both material nonlinearity (beyond linear elasticity) and deformation nonlinearity (large strains involving higher order displacement gradients) . A full stress-strain curve is generally required (Fig. 4). The Riks algorithm was developed for this type of analysis where an equilibrium solution is required for the unstable state. This algorithm is available in the ABAQUS Standard [3] for static analysis. With available laboratory-controlled burst tests for mock-up pipes and actual reservoirs, the finite element analysis was performed to 1) verify the deformation shape; 2) predict the failure location; 3) compare the calculated pressure-volume relationship to the measured data; and 4) develop failure criteria for predictive testing.

\section{Finite Element Model}

The configurations of the tritium reservoirs ${ }^{1}$ and the mockup pipes allow an axisymmetric finite element analysis ${ }^{2}$ to be employed. To compare with the test data, it is important to obtain the instantaneous volume change during pressurization. This is achieved by implementing the hydrostatic fluid elements in the ABAQUS analysis [3].

Incompressible hydraulic fluid behavior is assumed. These hydrostatic fluid elements (FAX2) are attached to the standard axisymmetric elements (CAX4) of the pressure vessel (reservoir) inside wall. Both the fluid pressure and the cavity volume can be monitored during the deformation.

Most of the results in this report for a prototypic test reservoir were obtained from a model with 705 elements and 719 nodes. There are 5 elements across the thickness of the reservoir sidewall. A larger model consisting of 3544 elements and 3564 nodes with 20 elements across the sidewall was also used to investigate the mesh sensitivity. It was concluded that the coarser mesh provided sufficient accuracy and was appropriate in this study.

\section{Comparison of Deformation}

A deformed finite element mesh at the predicted burst pressure was superimposed on the photograph of a burst mockup pipe. Figure 5 shows that the calculated shape agrees well with the post-burst specimen.

\footnotetext{
${ }^{1}$ The test specimens are prototypical and are not reservoirs in production.

${ }^{2}$ For exposed tritium reservoir, the post-test metallographic analysis found that mudflat cracks occurred in the inside wall of the reservoir. If the cracks are considered explicitly in the finite element analysis, the axisymmetric models can not be used. In the current continuum approach, the axisymmetric analysis is appropriate.
} 


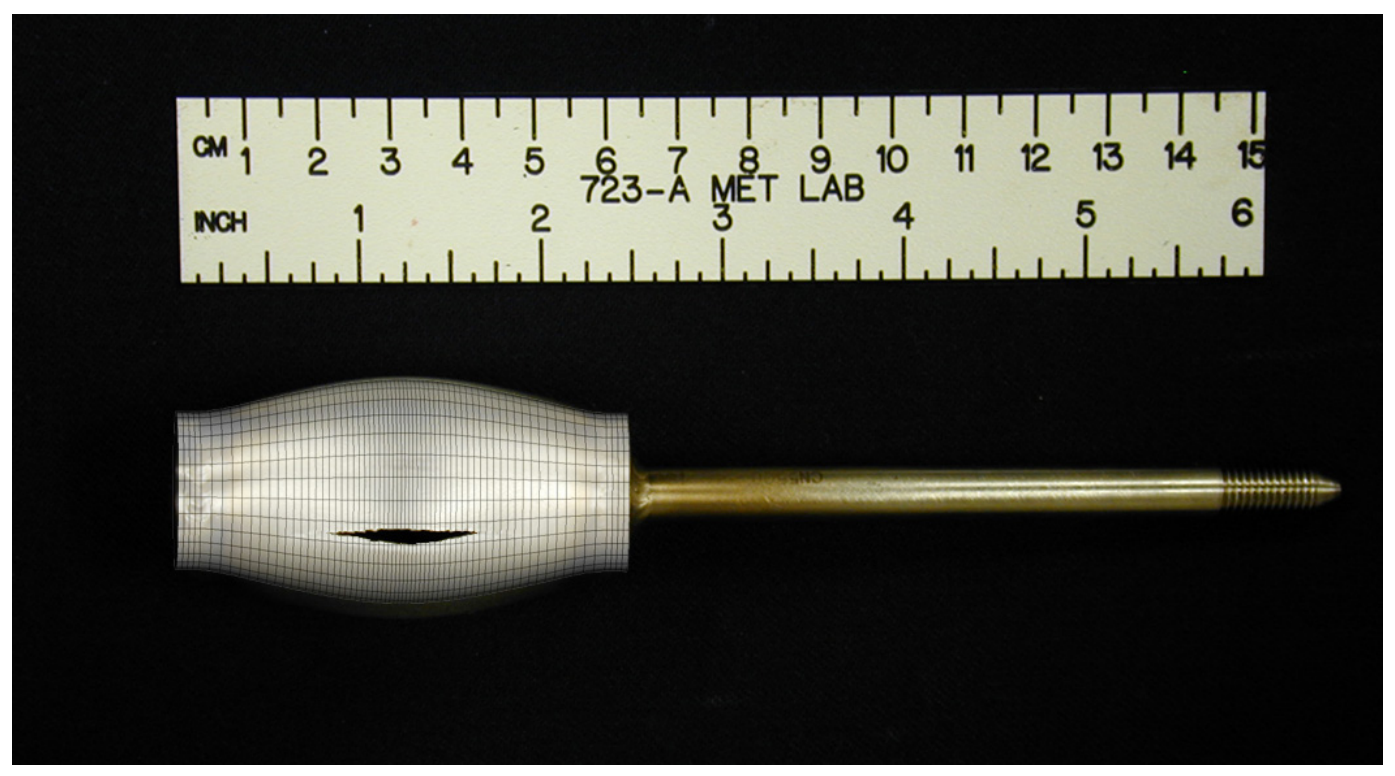

Figure 5 Post-burst configuration of a mockup pipe

\section{Prediction of Failure Location}

The Mises stress contours are plotted over the deformed shapes of several prototypic test specimens subject to burst test in Figures 6a, b, and c. Their axisymmetric finite element meshes are shown, respectively, in Figures 6d, e, and f. The warmer colors represent higher stress levels and coincide with the locations of failure. In general, the failure location is in the middle of the sidewall with uniform thickness, as can be seen in the photograph in Figure 5. However, as shown in Figure 6c, when a thinner cap was fabricated for the test specimen, the failure occurs in the cap region. This has been verified experimentally.

A detailed stress contour and the corresponding equivalent plastic strain contour are plotted in Figures 7a and 7b, respectively. It can be concluded that the stress or strain criterion would be equivalent in predicting failure in a burst test. However, the strainbased criterion may be favorable since the strains can be measured directly. Furthermore, stress variation is relatively insensitive near the failure moment due to the nature of the stress-strain curve, while the strains varies significantly and can be identified easily.

Figure 7 also indicates that the high stress/strain first occurs in the inside wall of the test specimen. This implies that the material fails first inside the cavity, then the failure propagates outward in a catastrophic manner. Note that the current finite element analysis is not designed for predicting post-failure configuration, including the size of the failure (cracking). 


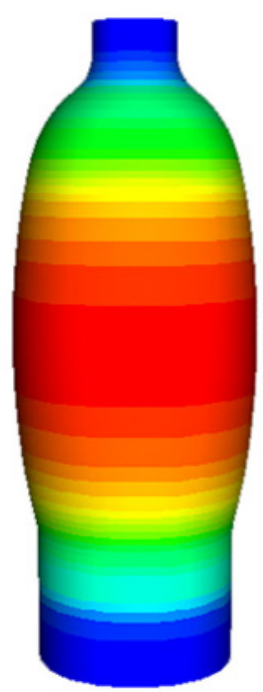

(a)

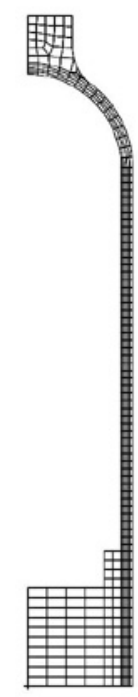

(d)

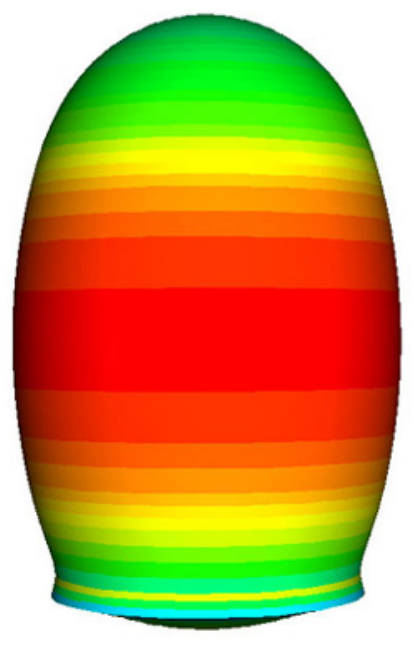

(b)

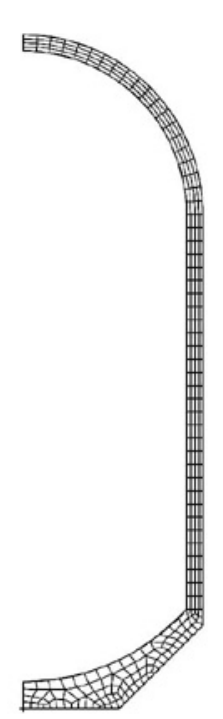

(e)

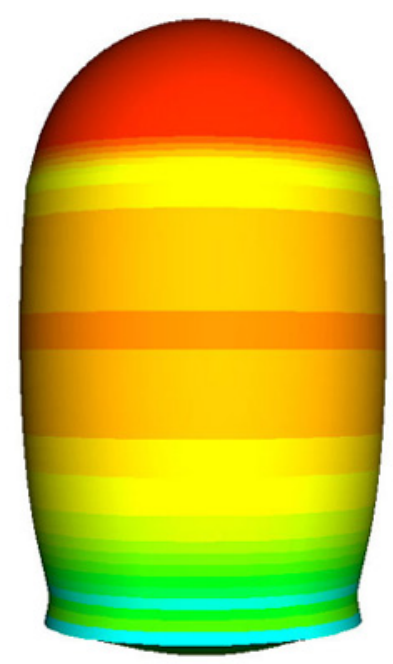

(c)

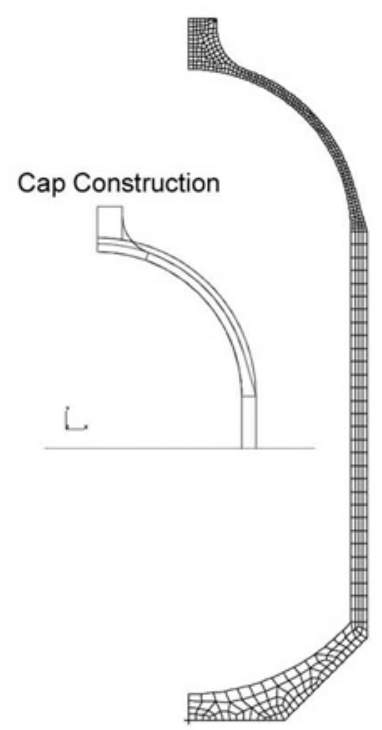

(f)

Figure 6 Mises stress contours (a, b, and c) and the finite element meshes (d, e, and f), respectively, for several prototypic burst test specimens with various designs 

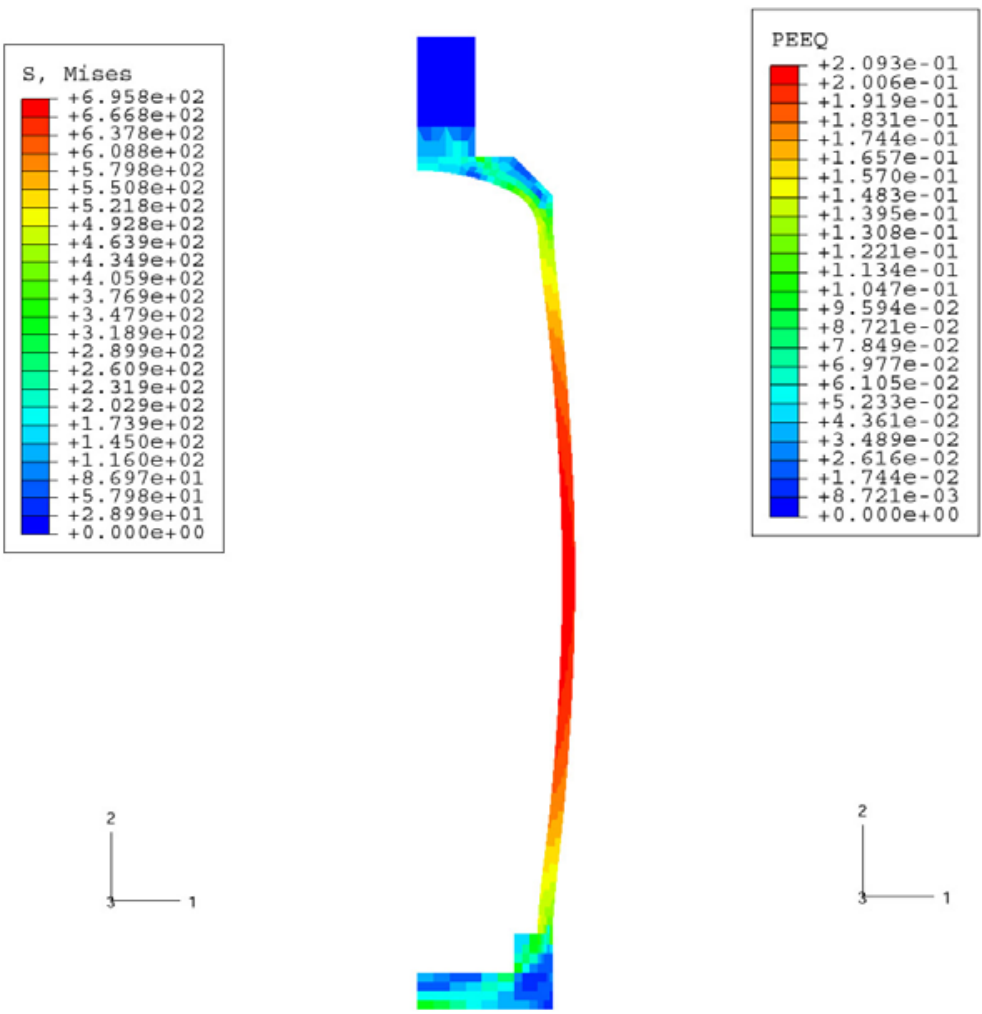

(a)

(b)

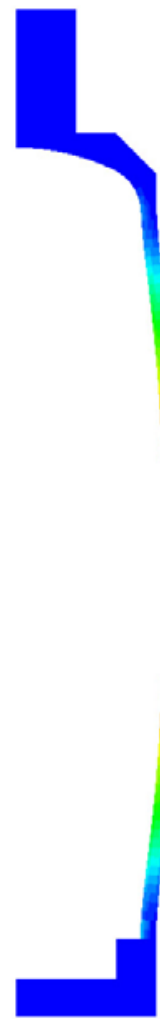

Figure 7 (a) Mises stress contour in MPa and (b) the corresponding equivalent plastic strain (PEEQ) contour for a typical test specimen

\section{Comparison of Finite Element Prediction and Test Data}

Burst test data of two prototypic reservoirs are plotted in Figure 8 in terms of volume ductility defined by $\Delta \mathrm{V} / \mathrm{V}_{\mathrm{o}}$, where $\Delta \mathrm{V}$ is the volume change and $\mathrm{V}_{\mathrm{o}}$ is the original volume. It should be noted that there is a slight difference in defining volume: in the finite element analysis, $\Delta \mathrm{V}$ or $\mathrm{V}_{\mathrm{o}}$ are referred to the cavity of the reservoir where the pressure is applied, while in the actual test, it is based on the entire volume of the test specimen as is measured directly by, for example, the displaced fluid in the test chamber. However, it is believe that the difference in volume change is within the inherent experimental error band because the majority of the deformation occurs in the cavity of the specimen.

When the stress-strain curve in Figure 4 (with yield stress $70 \mathrm{ksi}$ ) was used in the finite element analysis, the calculated result overestimated the experimental data. As noted earlier, the tensile properties were determined from materials harvested from prototypic tritium reservoirs. These properties for the specific reservoir specimens used in the burst tests had not been obtained but are expected to be within the allowable range for forged stainless steels (e.g., the yield stress can vary between 55 and $75 \mathrm{ksi}$ ). Therefore, the stress-strain curve in Figure 4, also shown in the inset of Figure 8, was scaled down to 
have a yield stress of $63 \mathrm{ksi}$. Figure 8 shows that the prediction and the test data agree well when the scaled stress-strain curve is used in the finite element calculations.

It should be mentioned that the peak pressure in Figure 8 before the curve bends over represents the burst pressure, and the corresponding value of $\Delta \mathrm{V} / \mathrm{V}_{\mathrm{o}}$ is the volume ductility at failure. The volume ductility is widely used as an index for material performance in tritium-loaded and aged reservoirs.

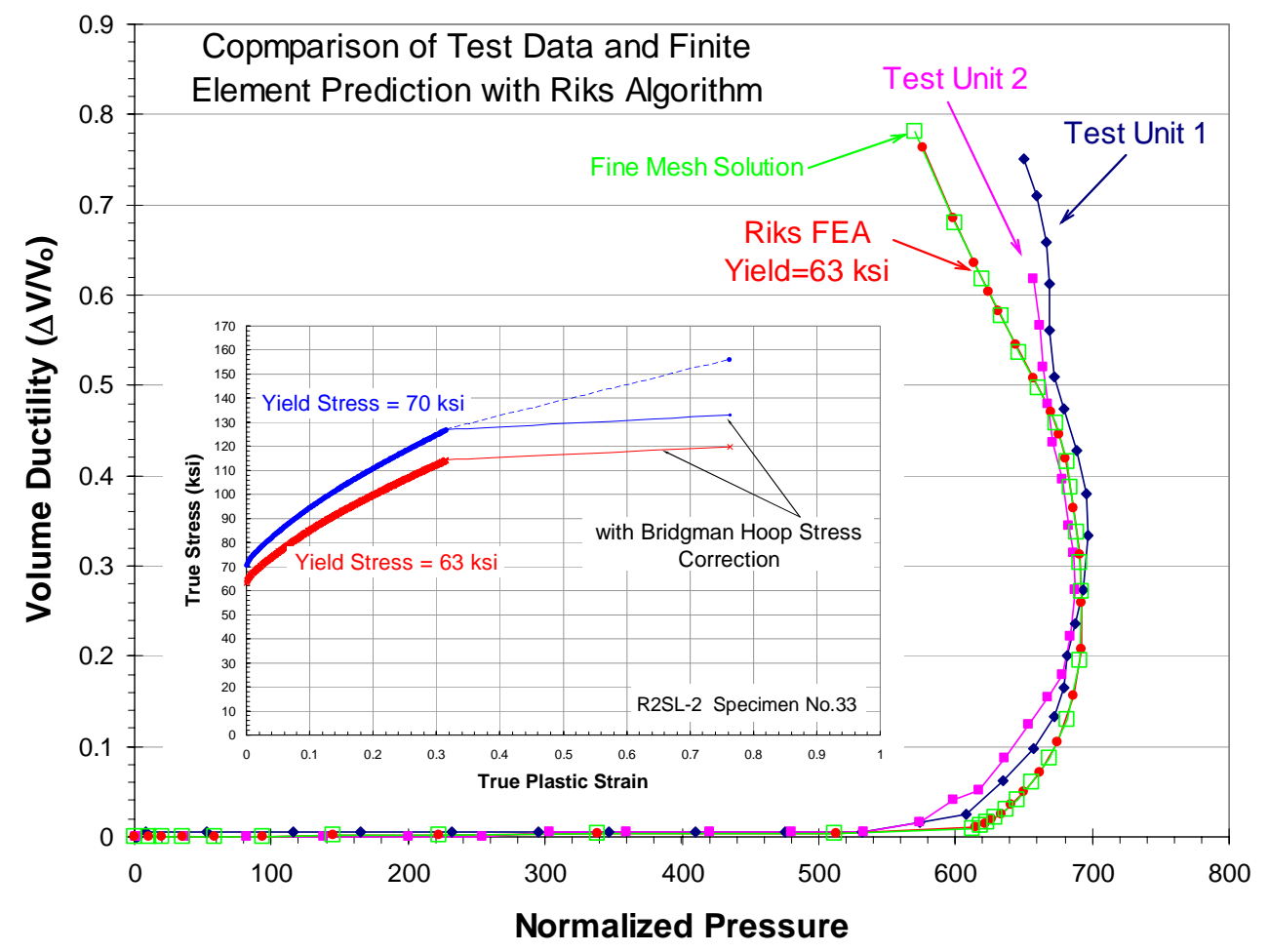

Figure 8 Comparison of the actual test data and the finite element prediction using a stress-strain curve with yield stress scaled to $63 \mathrm{ksi}$

\section{Failure Criterion for Burst Prediction}

It was noted in the tests that the burst pressure is less sensitive to the material property change caused by tritium exposure and decay than the burst volume ductility. However, the volume ductility $\left(\Delta \mathrm{V} / \mathrm{V}_{\mathrm{o}}\right)$ is observed to be significantly influenced by the presence of tritium and helium. As a result, a strain-based failure criterion, rather than stress-based, is sought in terms of the maximum plastic strain in the sidewall, where the failure is predicted to occur.

Figure 9 shows the variations of the pressure level and the volume ductility, respectively, as functions of the maximum equivalent plastic strain $\left(\varepsilon_{\mathrm{pl}, \mathrm{max}}\right)$ as the specimen is pressurized. It is obvious that the pressure varies slowly after the specimen is yielded. 
On the other hand, the plastic strain continues to rise in a nearly linear manner. In fact, the data point can be fit to an equation with very high least-square $\left(\mathrm{R}^{2}>0.999\right)$ :

$\Delta \mathrm{V} / \mathrm{V}_{\mathrm{o}}=1.25 \varepsilon_{\mathrm{pl}, \max }$

Therefore, for a general strain-based burst criterion, the following expression is proposed:

$\Delta \mathrm{V} / \mathrm{V}_{\mathrm{o}}=\mathrm{C} \varepsilon_{\mathrm{pl}, \mathrm{max}}$

where $\mathrm{C}$ is a proportional constant, which may be a function of reservoir geometry, material of construction, and tritium service history. In the present case, $\mathrm{C}=1.25$ and $\varepsilon_{\mathrm{pl}, \mathrm{max}}=22 \%$.

Note that this $\varepsilon_{\mathrm{pl} \text {,max }}$ is less than the limit of uniform elongation denoted by $\varepsilon_{\mathrm{UTS}}$ (the strain corresponding to UTS), which is about 32\% as shown in the inset of Figure 8 . The correlation between $\varepsilon_{\mathrm{pl} \text {,max }}$ and $\varepsilon_{\mathrm{UTS}}$ has not been established. However, $\varepsilon_{\mathrm{UTS}}$ is often used for failure criterion to avoid unstable, local necking [9], and is used as a crucial material performance indicator. Additional material testing for exposed reservoir materials and burst tests for reservoirs with matching material conditions are suggested to provide verification of the methodology for aged materials systems.

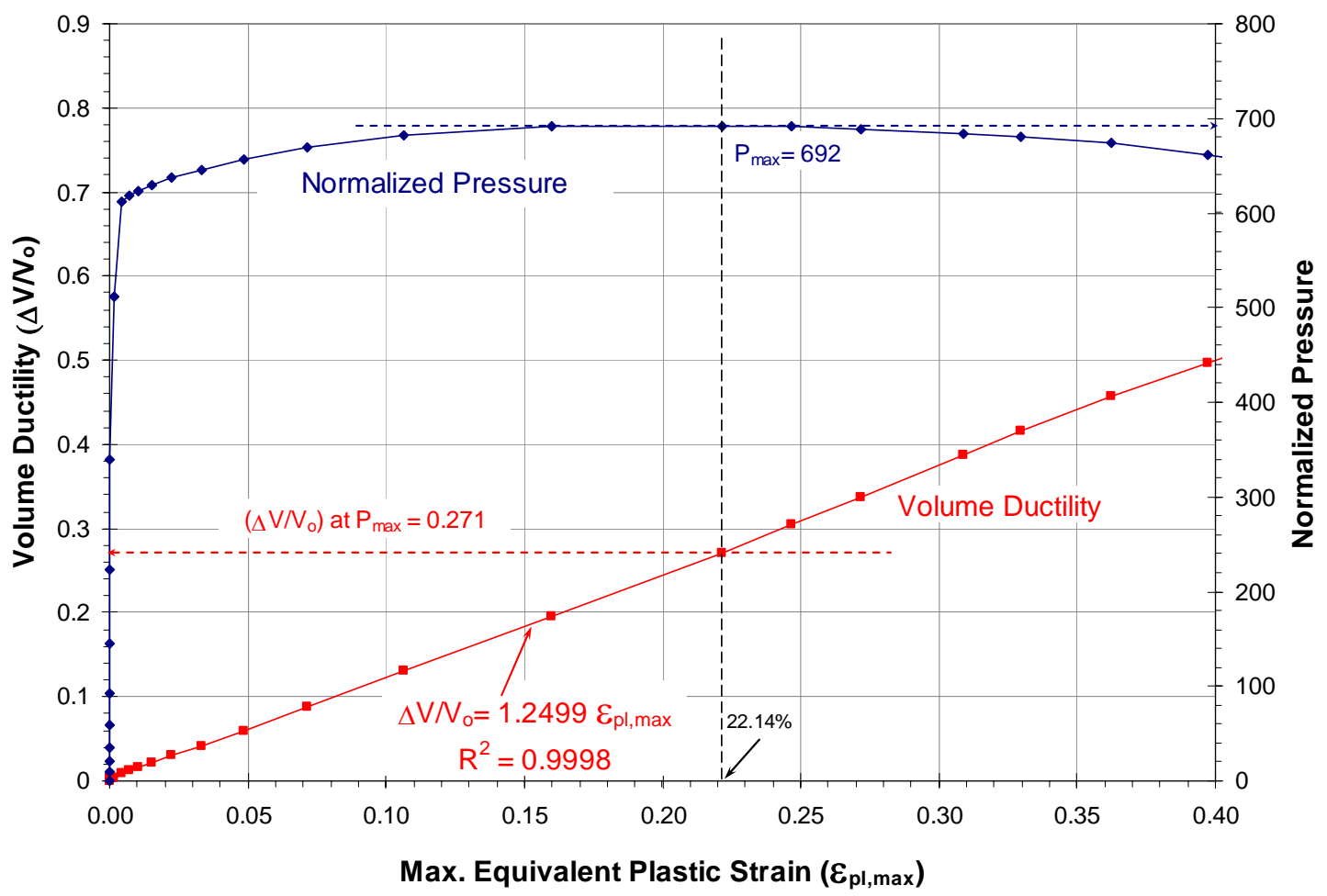

Figure 9 Burst pressure and volume ductility as functions of maximum plastic strain in the test specimen sidewall 


\section{PREDICTION OF TRITIUM-EXPOSED RESERVOIRS}

It is speculated that the failure of tritium-exposed reservoirs under burst test occurs soon after the mudflat cracks ${ }^{3}$ are formed in the inside wall where tritium absorption, diffusion, and decay to helium-3, occurs. It may also be reasonable to assume that these cracks are initiated at the yield stress of the exposed material. In the absence of tensile properties for the exposed material, two sets of material idealization were used for a fraction of the sidewall thickness that is affected by tritium: 1 ) the material behaves elastic- perfectly plastically (i.e., the maximum load-carrying capacity is limited by the yield stress); and 2) the material stress-strain curve is constructed to reflect the helium-3 concentration-dependent tensile properties reported by Robinson [10,11].

A fine-meshed finite element model was used in this part of analysis to take consideration of a better transition of the tensile properties from the exposed (inside wall) to the unexposed states (outside wall). This model contains 3544 elements and 3564 nodes, with 20 elements across the thickness of the sidewall. Both axisymmetric and hydrostatic fluid elements were used, as discussed earlier.

\section{Exposed Material: Elastic-Perfectly-Plastic Behavior}

With the assumption that the flow property of the exposed material may increase by $10 \%$ due to the dislocation pinning from the presence of helium-3, and that the loss of loadcarrying capacity due to the formation of mudflat cracks at the elevated yield stress (70 ksi), the elastic-perfectly plastic material (nonhardening) behavior is used for the inner sidewall, tritium-exposed material. In addition, as the flow stress in the cracked region reaches 70 ksi yield stress limit, the Young's modulus is arbitrarily reduced to about $1 / 2$ of its original stiffness due to cracking. This treatment was achieved by invoking the ABAQUS User's Subroutine "USDFLD" [3]. Note a more reasonable approach to set a low value for Young's modulus in the circumferential direction of the reservoir (anisotropic formulation) resulted in numerical difficulty. For the outer portion of the reservoir, the material properties remain unchanged and maintain the strain-hardening capability with a yield stress of $63 \mathrm{ksi}$. These two stress-strain curves used in the analysis are shown in the inset of Figure 10.

Note that this material idealization may not be realistic, but the purpose is to demonstrate the effect of tensile property change in part of the sidewall across the thickness. Therefore, 20, 40, and $60 \%$ of tritium penetration was assumed in the sidewall, respectively, and the material properties are assumed to be uniform within the affected region. The results are plotted in Figure 10 for the determination of the burst pressure and the volume ductility (similar to Fig. 8). It can be seen that all the predicted burst

\footnotetext{
${ }^{3}$ In a cylindrical vessel under extended tritium service, the mudflat cracks are numerous axial cracks which may be initiated at high pressure in the inside diameter of the circular cross-section and grow radially into the vessel wall in the thickness direction, but arrested near the degraded (exposed) material boundary. As the internal pressure continues to increase, one of the mudflat cracks, in probabilistic sense, may eventually advance through the vessel wall to form a single, catastrophic crack as seen in the burst test.
} 
pressures are within 5\% of that for the unexposed case. However, a pronounced effect can be seen in the volume ductility. Figure 11 shows that the volume ductility reduced to one-half of the unexposed case when the tritium penetration is $30 \%$ of the wall thickness. This phenomenon has been observed experimentally.

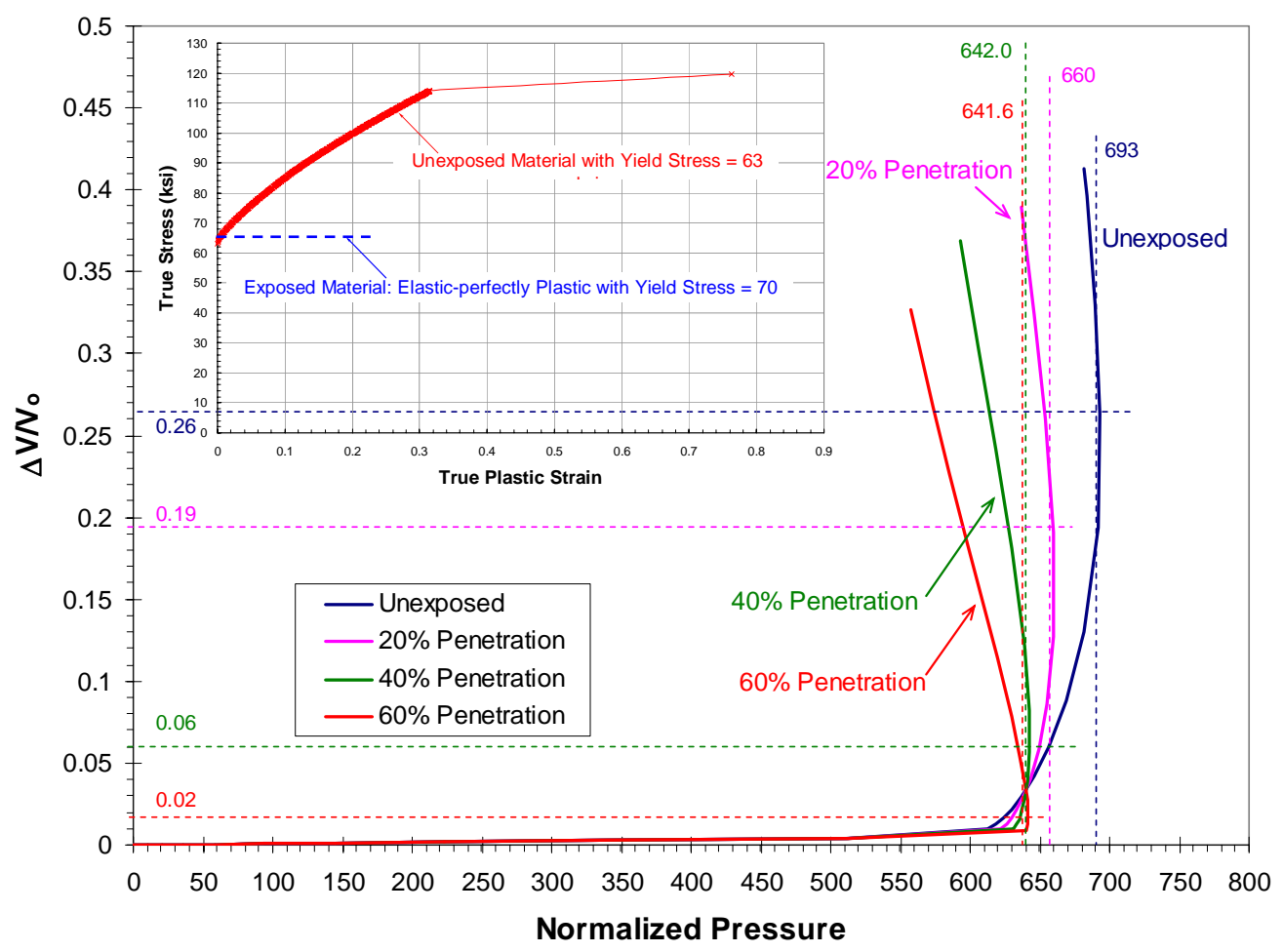

Figure 10 Determination of burst instability as a function of thickness percentage that is affected by tritium in the sidewall of the specimen

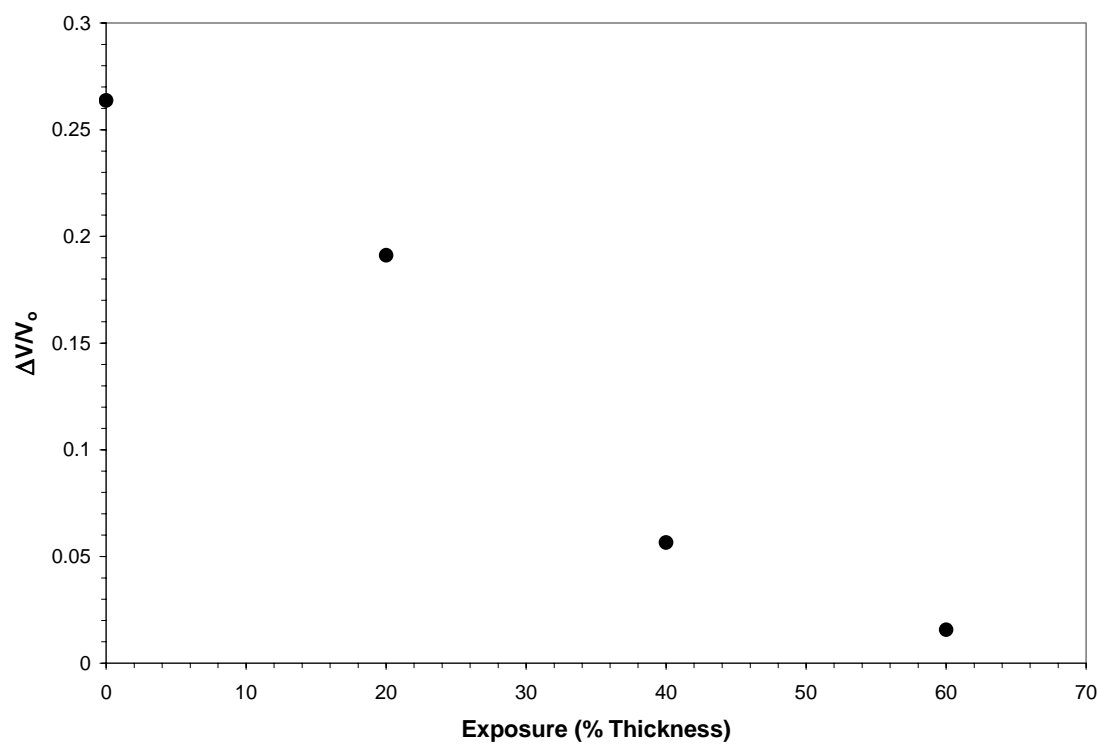

Figure 11 Reduction of ductility as a function of tritium-affected material in the sidewall 


\section{Exposed Material - Helium-3 Concentration-Dependent Tensile Properties}

The tritium effects on the tensile properties have been investigated extensively (e.g., [1013]) but are incomplete due to many variables such as the source of helium and various exposure scenarios. Typically, a stainless steel responds to tritium exposure in such a way depicted in Figure 12 [12]: the flow stress is increased slightly, but the ductility is reduced significantly, due to the presence of decay helium-3 and hydrogen embrittlement. In Figure 12, this phenomenon appears more pronounced in the annealed material than in the high energy rate forged (HERF) steel.

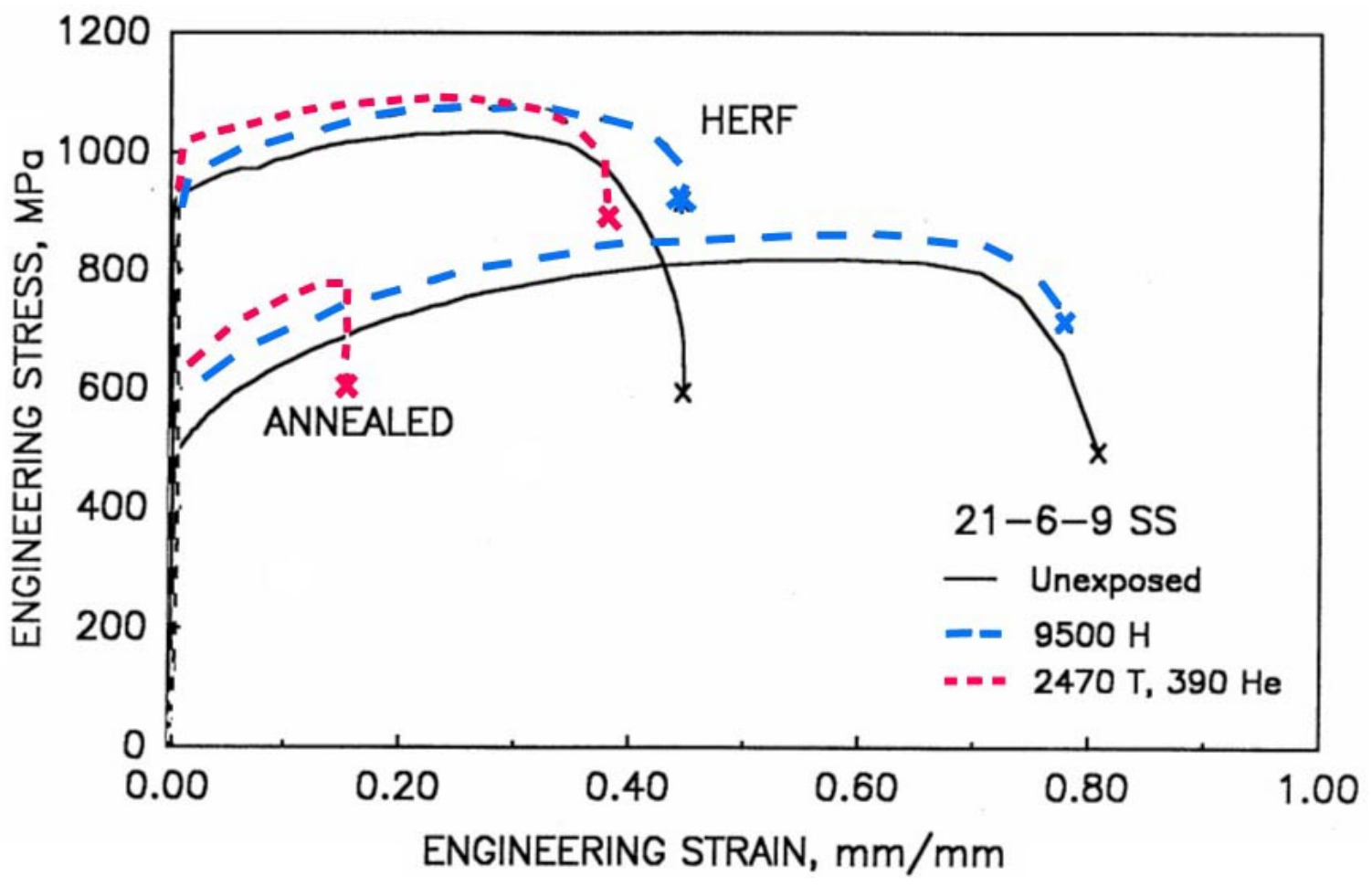

Figure 12 Typical tensile property change due to tritium exposure (Reproduced from [12])

Robinson [10,11] reported the effects of tritium and decay helium on tensile properties for austenitic stainless steels HERF 304L, 316, and 21-6-9. The miniature tensile specimens were charged with tritium and allowed sufficient time to saturate the gage section. Various aging times were used for the accumulation of helium-3 resulting from tritium decay. The tensile properties as functions of helium concentration can be found in Reference [10] and are reproduced in Figure 13. Similar to Figure 12 [12], the yield stress and UTS are elevated as the helium concentration increases, while the uniform elongation, total elongation, and reduction of area are decreased. Note that the charged tritium was not totally removed from these tensile specimens before testing. 


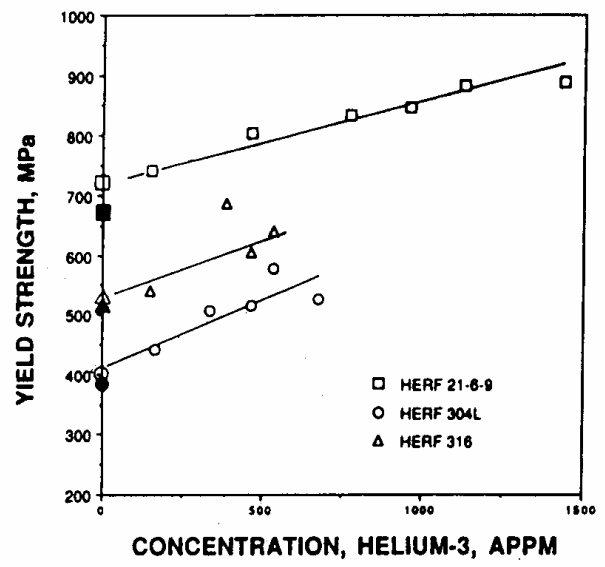

(a)

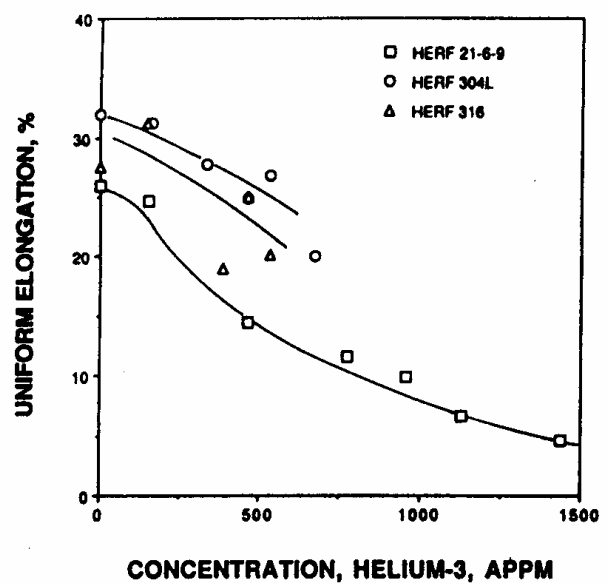

(c)

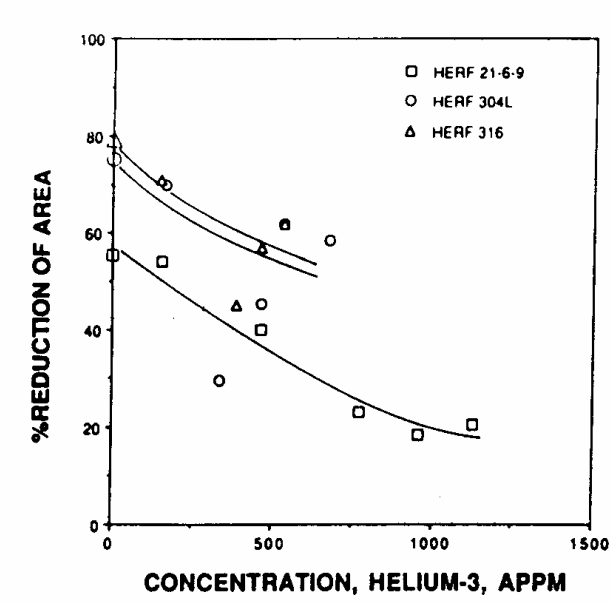

(e)

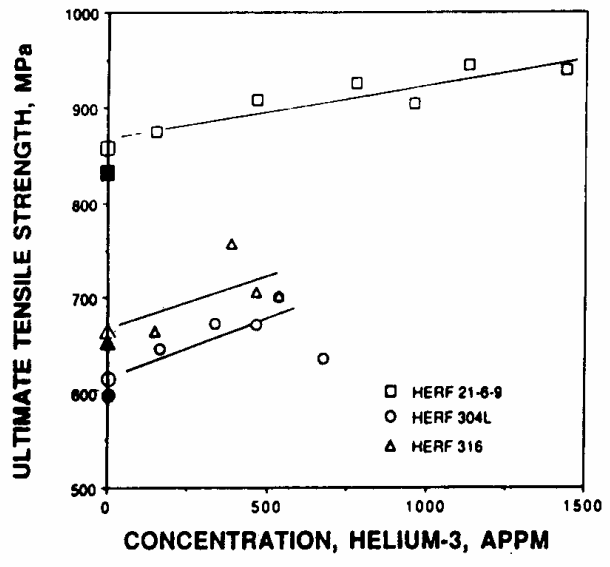

(b)

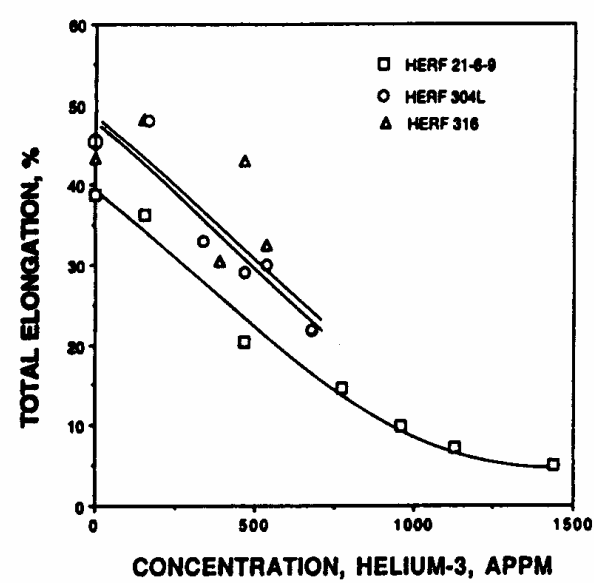

(d)

Figure 13 Tensile property change with respect to helium-3 concentration for various stainless steels (Reproduced from [10]) 
Table 1 lists the tensile properties that were extracted from Figure 13 with the helium concentration at 0 (hydrogen charged specimens), 125, 250, and 500 APPM. The zero helium concentration was achieved with the hydrogen-charged specimens [10,11]. A set of simplified true stress-true plastic strain curves can be constructed (Fig. 14). These stress-plastic strain curves are linear because only the yield stress and the (true) UTS data points were used. The failure point for each stress-strain curve can not be identified because the failure stresses were not reported in References [10,11]. Therefore, the range of validity of the stress-strain curves in Figure 14 is up to the UTS, and no Bridgman correction is needed.

Table 1 Tensile property of HERF 316 due to helium concentration

\begin{tabular}{|c|c|c|c|c|c|c|c|}
\hline $\begin{array}{l}\text { Helium } \\
\text { Concen- } \\
\text { tration }\end{array}$ & $\begin{array}{l}\text { Yield } \\
\text { Stress }\end{array}$ & $\begin{array}{l}\text { UTS } \\
\text { (Engi- } \\
\text { neering) }\end{array}$ & $\begin{array}{l}\text { UTS } \\
\text { (True) }\end{array}$ & $\begin{array}{c}\text { Uniform } \\
\text { Elonga- } \\
\text { tion }\end{array}$ & $\begin{array}{c}\text { Uniform } \\
\text { Elongation } \\
\left(\varepsilon_{\text {UTS }}\right)\end{array}$ & $\begin{array}{l}\text { Total } \\
\text { Elonga- } \\
\text { tion }\end{array}$ & $\begin{array}{c}\text { Reduction } \\
\text { of Area }\end{array}$ \\
\hline (appm) & $\begin{array}{c}\text { MPa } \\
(\mathrm{ksi})\end{array}$ & $\begin{array}{c}\mathrm{MPa} \\
(\mathrm{ksi})\end{array}$ & $\begin{array}{c}\mathrm{MPa} \\
(\mathrm{ksi})\end{array}$ & $\begin{array}{l}\text { (engi- } \\
\text { neering) }\end{array}$ & True & $\begin{array}{l}\text { (engi- } \\
\text { neering) }\end{array}$ & $\begin{array}{c}\text { (engi- } \\
\text { neering) }\end{array}$ \\
\hline 0 & $\begin{array}{c}530 \\
(77)\end{array}$ & $\begin{array}{c}670 \\
(97)\end{array}$ & $\begin{array}{c}878 \\
(127)\end{array}$ & 0.31 & 0.27 & 0.50 & 0.80 \\
\hline 125 & $\begin{array}{c}550 \\
(80)\end{array}$ & $\begin{array}{c}680 \\
(99)\end{array}$ & $\begin{array}{c}877 \\
(127)\end{array}$ & 0.29 & 0.25 & 0.45 & 0.71 \\
\hline 250 & $\begin{array}{c}570 \\
(83)\end{array}$ & $\begin{array}{c}690 \\
(100)\end{array}$ & $\begin{array}{c}876 \\
(127)\end{array}$ & 0.27 & 0.24 & 0.40 & 0.66 \\
\hline 500 & $\begin{array}{c}630 \\
(91)\end{array}$ & $\begin{array}{c}725 \\
(105)\end{array}$ & $\begin{array}{c}891 \\
(129)\end{array}$ & 0.23 & 0.20 & 0.31 & 0.58 \\
\hline
\end{tabular}

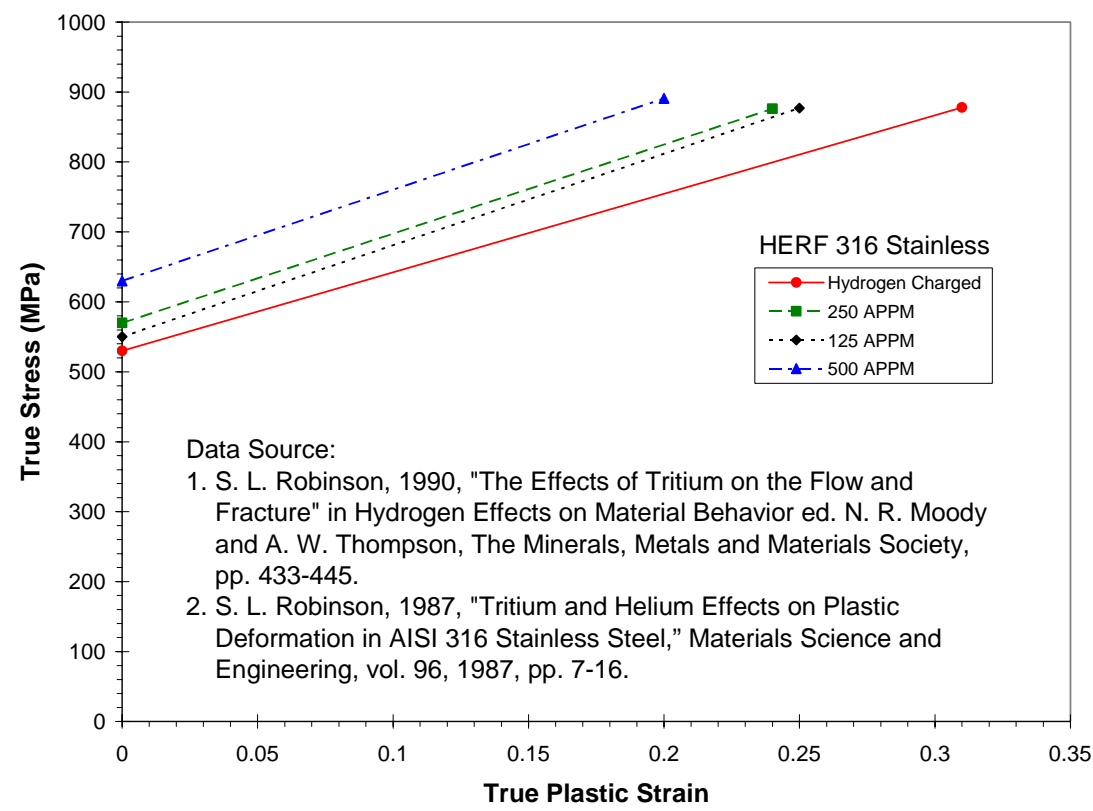

Figure 14 Simplified stress-strain curves for exposed HERF 316 at various helium concentrations 
In the finite element analysis, the unexposed portion of the reservoir used the tensile properties obtained from the hydrogen-charged, no decay helium specimens (the lowest stress-strain curve in Fig. 14). For exposed materials with helium concentration of 125, 250, or 500 APPM, the constitutive behavior was treated similarly as in the previous section (Exposed Material: Elastic-Perfectly-Plastic Behavior) to account for the loss of load-carrying capacity due to the formation of mudflat cracks. That is, the Young's modulus was reduced to $1 / 2$ of the typical value, and the nonhardening behavior was assumed with the stress plateau corresponding to the respective, elevated yield stress (80, 83, or $91 \mathrm{ksi})$. Again, the change of material properties was controlled by the ABAQUS User's Subroutine "USDFLD” [3]. The linear stress-plastic strain curves in Figure 14 for helium-bearing materials can not be used when cracking occurs.

The depths of tritium penetration for each helium concentration level were assumed to be $10,20,40$, and $60 \%$ of the sidewall thickness. The calculated results are plotted in Figures 15 to 17 to represent the evolution of volume change and pressure during the burst test. These figures are used to determine the burst pressure and the corresponding volume ductility for each of the case. Note that the volume change and the cavity pressure of the specimen are normalized, respectively, by those for the zero-helium concentration case (hydrogen charged), for which the burst pressure is $11.16 \mathrm{ksi}$ (77 $\mathrm{MPa}$ ) and $\Delta \mathrm{V} / \mathrm{V}_{\mathrm{o}}$ is 0.286 . Again, the predicted burst pressures are within $5 \%$ of that for the helium-free material. However, the reduction of volume ductility is significant when helium is present. The relationship between the volume ductility and the helium concentration for various depths of tritium penetration through the thickness can be seen in Figure 18.

Figure 18 can be used to determine the volume ductility for an exposed reservoir without knowing its service history as long as the helium-3 concentration can be somehow estimated independently. 


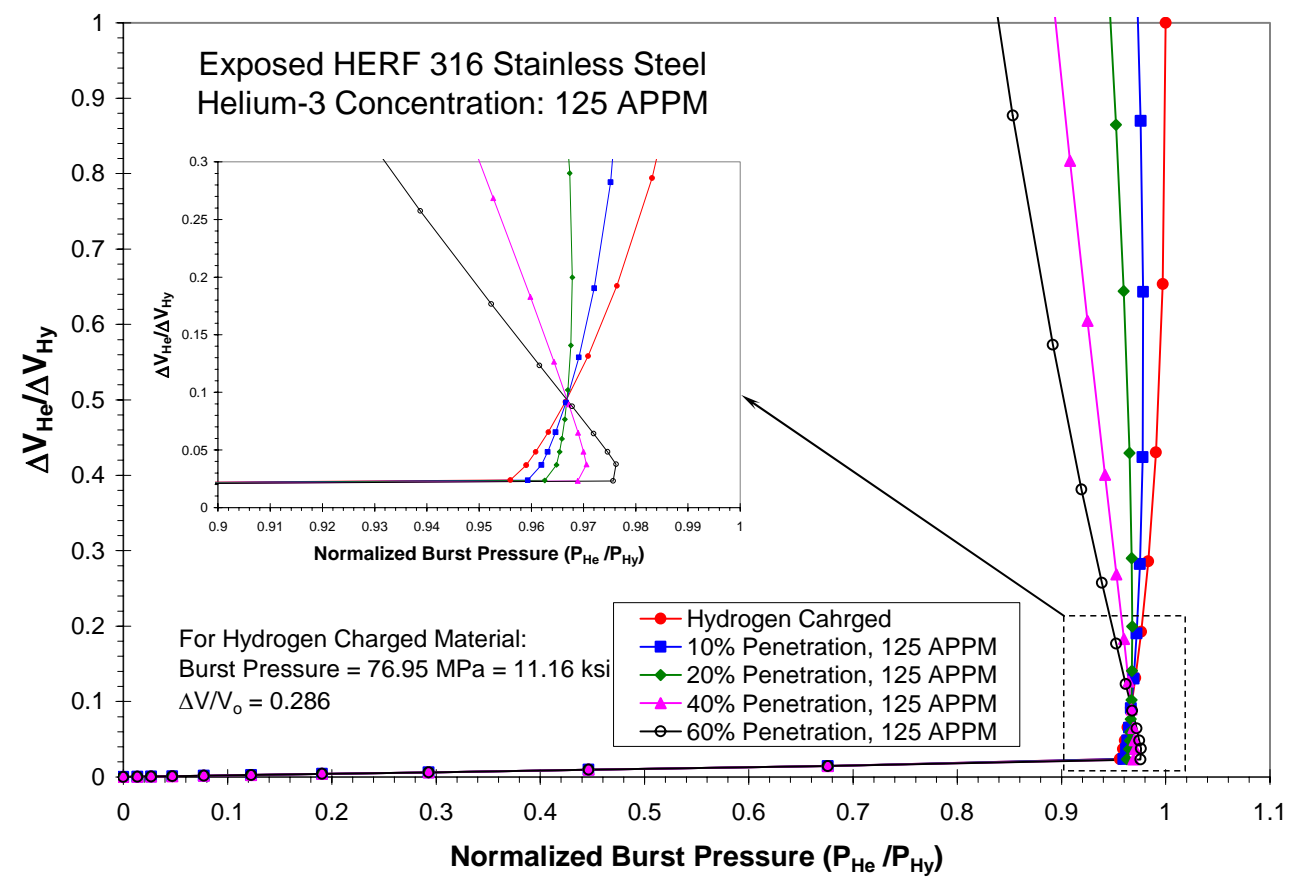

Figure 15 Determination of volume reduction and burst pressure for helium concentration 125 APPM at various depths of penetration

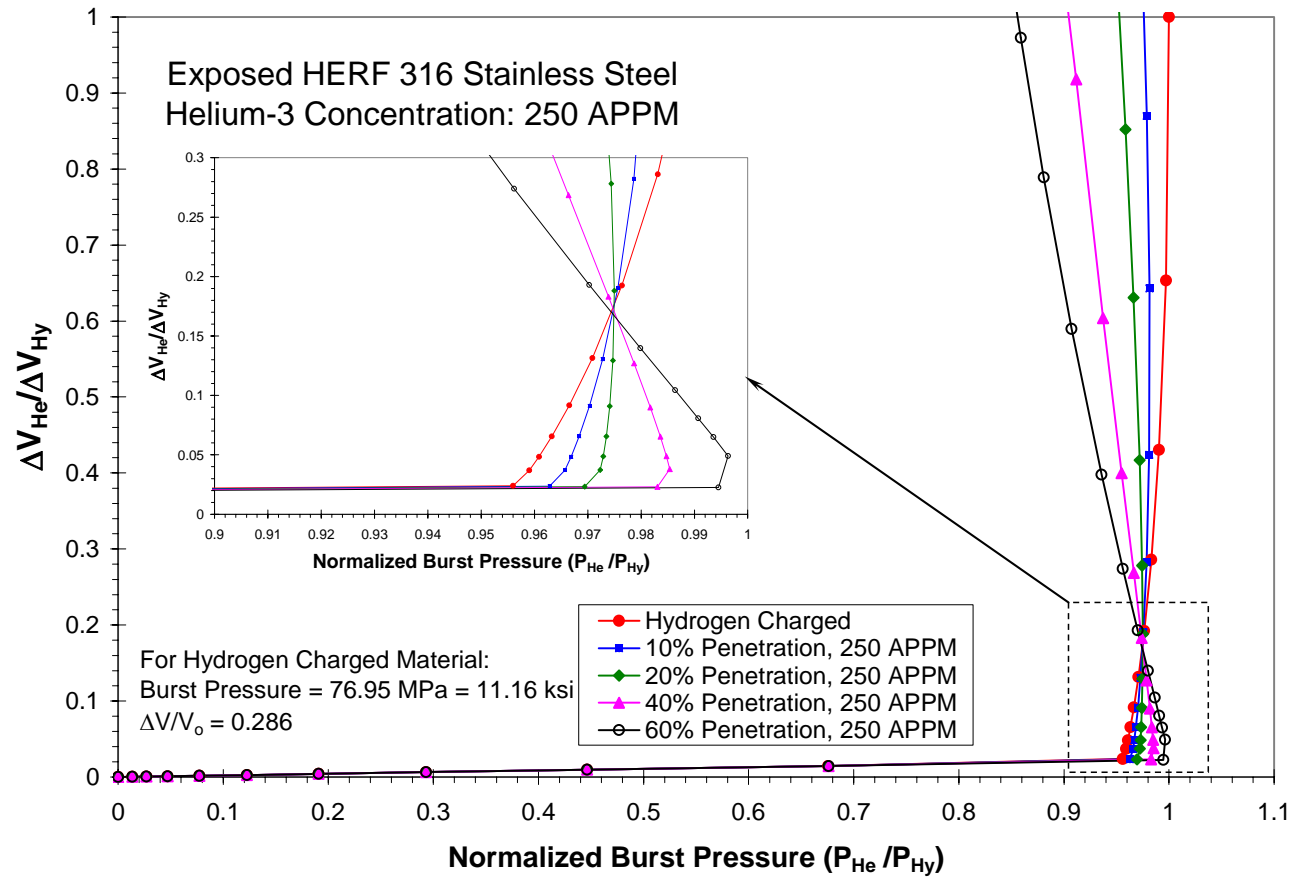

Figure 16 Determination of volume reduction and burst pressure for helium concentration 250 APPM at various depths of penetration 


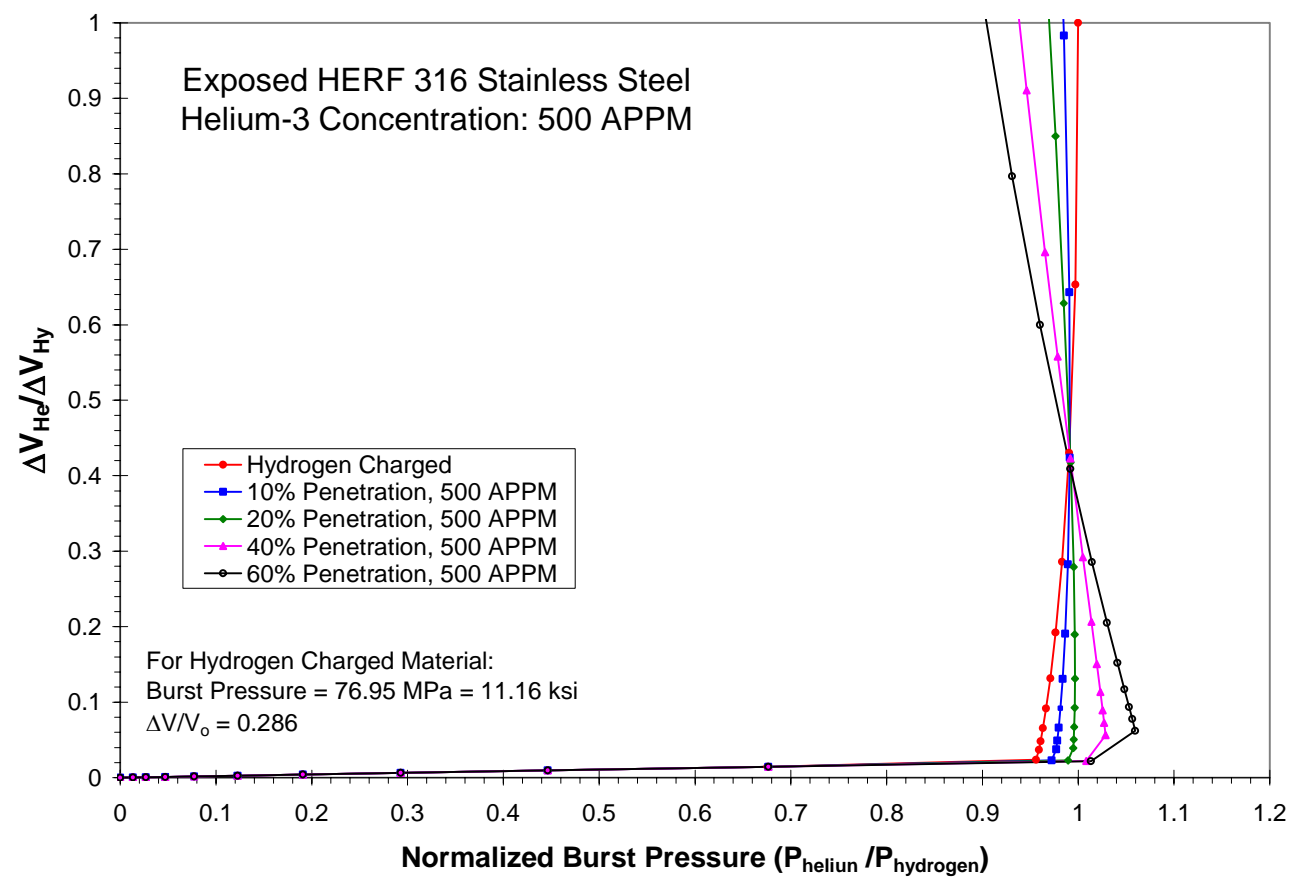

Figure 17 Determination of volume reduction and burst pressure for helium concentration 500 APPM at various depths of penetration

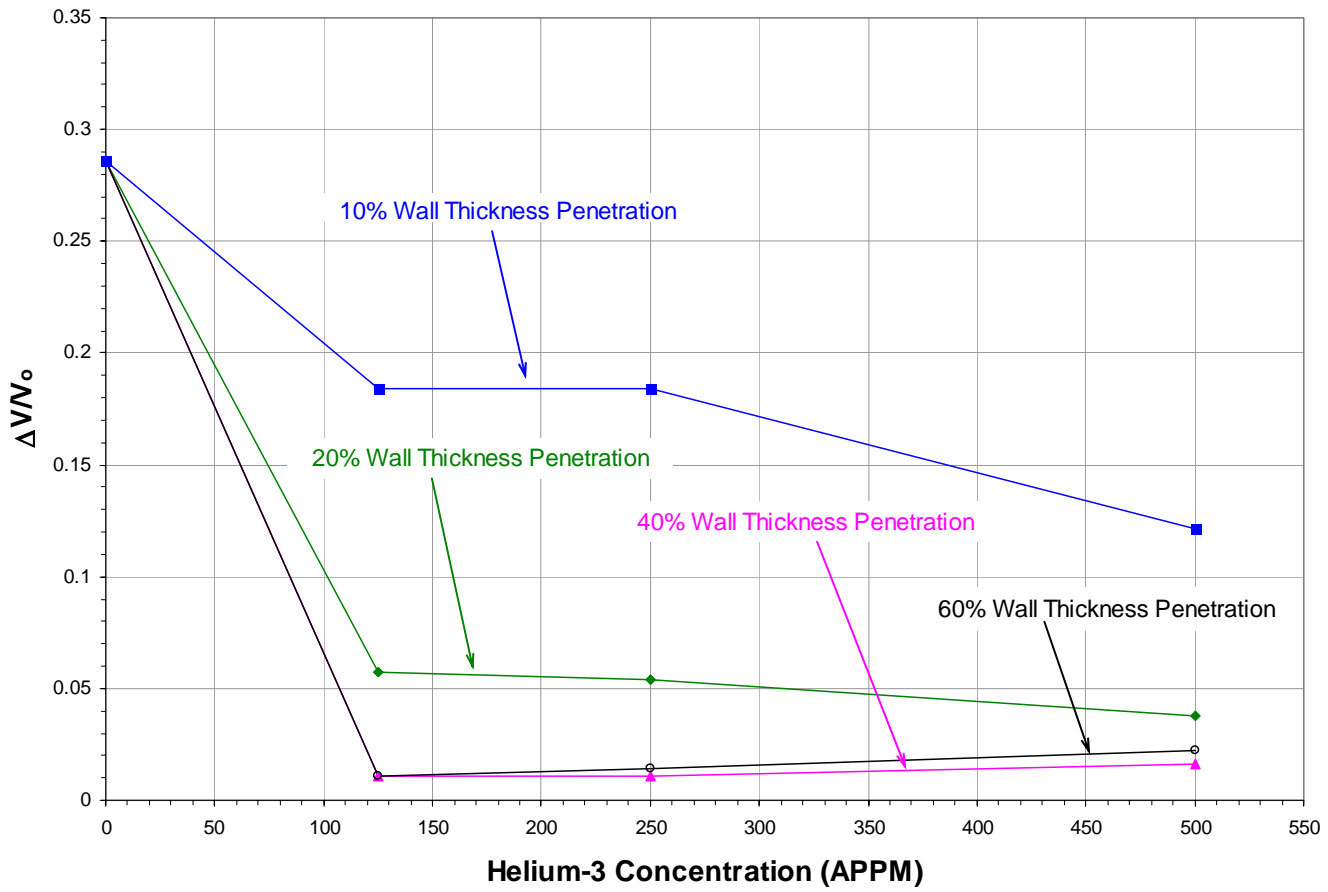

Figure 18 Volume reduction as a function of helium concentration for various depths of penetration 
It would be interesting to note that the material in the inner sidewall, where the tritium and helium are present, may sometimes carry higher load (stress) as seen in Figure 19a for the case of high helium concentration (500 APPM) and deep tritium penetration (60\%). This is caused by the higher flow stress (Table 1). However, this material is penalized by the lower ductility (Table 1) while the plastic strain remains high in the inner sidewall (Fig. 19b). From the current formulation of the material constitutive law (Fig. 14), it seems that there is a subtle balance among the flow stress, ductility, and the depth of penetration. This may explain the unexpected behavior of $\Delta \mathrm{V} / \mathrm{V}_{\mathrm{o}}$ at higher helium concentration with deep thickness penetration ( $>40 \%)$. On the other hand, for an actual tritium reservoir in service, deep tritium penetration with high helium concentration in the sidewall may be unlikely to occur. Figure 19 is used for illustration purpose.
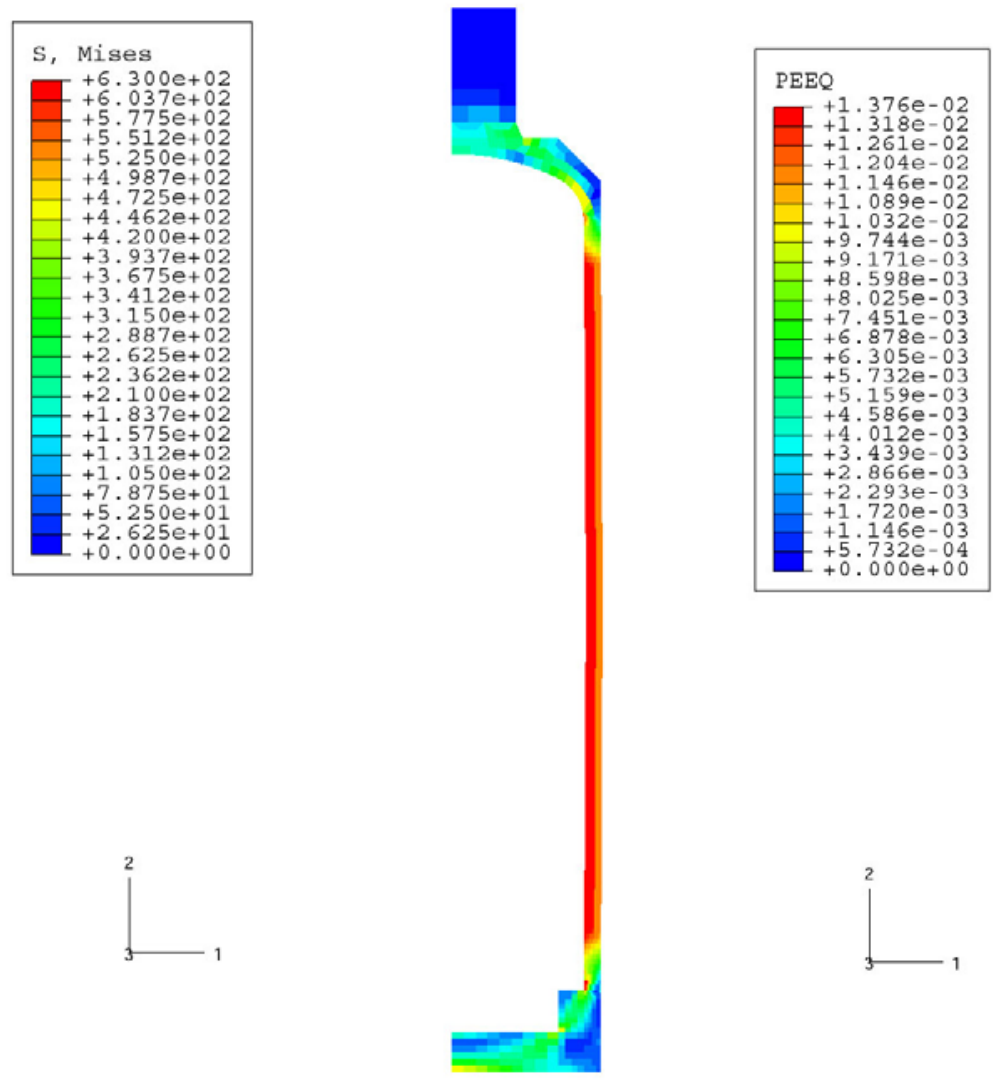

(a)

(b)

Figure 19 Contours of (a) Mises stress in MPa and (b) equivalent plastic strain (PEEQ) in a test specimen with $60 \%$ of sidewall thickness containing helium with concentration of 500 APPM 


\section{DISCUSSION AND CONCLUSIONS}

The finite element procedure developed under the PDRD program has demonstrated that the burst pressure and volume ductility can be predicted for unexposed tritium reservoirs (Fig. 8). However, for the previously loaded reservoirs, only qualitatively consistent results can be reported, that is, the burst pressures remain similar but the ductility is significantly reduced as the exposure time increases. A strong dependence of volume ductility on the helium concentration has been shown with an idealized material idealization. For example, when a uniform distribution of helium with 100 APPM occurred in $20 \%$ of the reservoir inside wall, the volume ductility is only $1 / 3$ of that for a helium-free material (Fig. 18).

Because the tritium and helium concentration profiles are functions of the initial condition, duration of aging, and the off-gas temperature, etc., the detailed fabrication information and service history are essential to create a realistic finite element model and to select appropriate material stress-strain curves for accurate prediction of the burst properties. A systematic approach with a carefully selected test matrix, and a complete material property database should be developed.

All burst tests for the exposed reservoirs show the presence of multiple crack networks on the inside wall. These cracks are oriented longitudinally in the case of cylindrical vessels. The lack of understanding of the cracking process poses a serious difficulty in accurate prediction of tritium-affected burst properties. The experimental observations and the present analysis strongly suggest that the crack nucleation and the depth of propagation play important roles in the drastic decrease of burst volume ductility for the exposed reservoirs. In order to further improve the modeling prediction capability, experimental efforts are needed to determine the cracking mechanism under burst test conditions. This may be achieved by a series of testing of identically exposed reservoirs, each subjected to different pressure level up to burst and followed by destructive examination for cracking; or by interrupting a single burst test which is coupled with acoustic emission and nondestructive ultrasonic examinations to monitor the crack initiation and to size the growing cracks. The numerical procedure to simulate the mechanical response of the cracked material can be formulated after the cracking event is properly characterized.

\section{ACKNOWLEDGMENTS}

The authors wish to acknowledge the in depth technical discussions with Tom Warren, Tom Walters, Ed Majzlik, and Baker White of SRNL/HTS. Some reservoir material information was obtained from Bruce Wilkinson of Los Alamos National Laboratory. The PDRD program support from Bob Rabun is greatly appreciated. 


\section{REFERENCES}

[1] Morgan, M. J. and Imrich, K. J., "Electric Discharge Machining Techniques for Evaluating the Effects of Tritium on Materials (U)," WSRC-TR-2003-00490 Rev. 0, Westinghouse Savannah River Company, Aiken, South Carolina, February 2004.

[2] Imrich, K. J. and Morgan, M. J., "Electric Discharge Machining of a Tritium Exposed Reservoir for Mechanical Property Testing (U),” WSRC-TR-2005-00403 Rev. 0, Westinghouse Savannah River Company, Aiken, South Carolina, September 2005.

[3] ABAQUS General Purpose Finite Element Program, ABAQUS Inc., Providence, Rhode Island.

[4] Bridgman, P. W., “The Stress Distribution at the Neck of a Tension Specimen,” Transactions of American Society for Metals, vol. 32, 1944, pp. 553-574.

[5] Kao, G. C., Lam, P. S., Barnes, D. M., "Material Testing Plan for Archival Carbon Steel Piping (U),” WSRC-TR-92-249, Westinghouse Savannah River Company, Aiken, South Carolina, May 1992.

[6] Stoner, K. J., Sindelar, R. L., and Caskey, G. R. , Jr., “Reactor Materials Program Baseline Material Property Handbook - Mechanical Properties of 1950’s Vintage Stainless Steel Weldment Components (U),” WSRC-TR-91-10, Westinghouse Savannah River Company, Aiken, South Carolina, April 1991.

[7] Dowling, N. E., Mechanical Behavior of Materials: Engineering Methods for Deformation, Fracture, and Fatigue, Prentice Hall, Englewood Cliffs, New Jersey, 1993.

[8] Zhang, Z. L., Hauge, M., Ødegård, and Thaulow, C., "Determining material true stress-strain curve from tensile specimens with rectangular cross-section," International Journal of Solids and Structures, Vol. 36, 1999, pp. 3497-3516.

[9] Sindelar, R. L., “Tensile Properties of Type 304/304L Stainless Steel for Impact Deformation Analysis of Nuclear Materials Containers (U),” SRT-MTS-93-3113, Interoffice Memorandum, Westinghouse Savannah River Company, Aiken, South Carolina, November 10, 1993.

[10] Robinson, S. L., "The Effects of Tritium on the Flow and Fracture of Austenitic Stainless Steels", in Hydrogen Effects on Material Behavior, ed. A. W. Thompson and N. R. Moody, The Minerals, Metals \& Materials Society, 1990, pp. 433-445.

[11] Robinson, S. L., "Tritium and Helium Effects on Plastic Deformation in AISI 316 Stainless Steel,” Materials Science and Engineering, vol. 96, 1987, pp. 7-16.

[12] Morgan, M. J., "The Effects of Hydrogen Isotopes and Helium on the Flow and Fracture Properties of 21-6-9 Stainless Steel,” Proc. Fine Symposium, ed. P. K. Liaw, J.R. Weertman, H. L. Marcus, and J. S. Santner, Warrendale, PA., TMS, 1990, pp. 105-111.

[13] Louthan, Jr., M. R., “Tritium Decay, Irradiation and Hydrogen/Helium Effects on Type 316L Austenitic Stainless Steel,” WSRC-MS-2001-00040, Westinghouse Savannah River Company, Aiken, South Carolina, 2001. 
REPORT WSRC-TR-2005-00251

\title{
DISTRIBUTION
}

\section{SAVANNAH RIVER SITE}

\author{
R. L. Rabun, III, 246-H \\ N. C. Iyer, 773-41A \\ R. L. Sindelar, 773-41A \\ S. L. West, 773-A \\ R. T. Walters, 773-A \\ T. J. Warren, 773-A \\ E. J. Majzlik, Jr, 773-A \\ E. G. Caveness, 773-A \\ M. B. White, Jr., 234-H \\ K. J. Imrich, 773-A \\ T. M. Adams, 773-41A \\ E. A. Clark, 773-A \\ K. H. Subramanian, 773-A \\ M. J. Morgan, 773-A \\ P. S. Lam, 773-41A
}

